\title{
Predicting Environmental Mitigation Requirements for Hydropower Projects through the Integration of Biophysical and Socio-Political Geographies
}

\section{Christopher R. DeRolph*a ${ }^{* a}$ Michael P. Schramm ${ }^{a}$, and Mark S. Bevelhimer ${ }^{a}$}

a Oak Ridge National Laboratory, Environmental Sciences Division, PO Box 2008, 1 Bethel Valley Road, Oak Ridge, TN 37831-6038

*corresponding author: derolphcr@ornl.gov

This manuscript has been authored by UT-Battelle, LLC under Contract No. DE-AC05-00OR22725 with the U.S. Department of Energy. The United States Government retains and the publisher, by accepting the article for publication, acknowledges that the United States Government retains a non-exclusive, paid-up, irrevocable, world-wide license to publish or reproduce the published form of this manuscript, or allow others to do so, for United States Government purposes. The Department of Energy will provide public access to these results of federally sponsored research in accordance with the DOE Public Access Plan(http://energy. gov/downloads/doe-public-access-plan). 


\section{ABSTRACT}

Uncertainty about environmental mitigation needs at existing and proposed hydropower projects makes it difficult for stakeholders to minimize environmental impacts. Hydropower developers and operators desire tools to better anticipate mitigation requirements, while natural resource managers and regulators need tools to evaluate different mitigation scenarios and order effective mitigation. Here we sought to examine the feasibility of using a suite of multi-faceted explanatory variables within a spatially explicit modeling framework to fit predictive models for future environmental mitigation requirements at hydropower projects across the conterminous U.S. Using a database comprised of mitigation requirements from more than 300 hydropower project licenses, we were able to successfully fit models for nearly 50 types of environmental mitigation and to apply the predictive models to a set of more than 500 nonpowered dams identified as having hydropower potential. The results demonstrate that mitigation requirements are functions of a range of factors, from biophysical to socio-political. Project developers can use these models to inform cost projections and design considerations, while regulators can use the models to more quickly identify likely environmental issues and potential solutions, hopefully resulting in more timely and more effective decisions on environmental mitigation.

Keywords hydropower, mitigation, modeling, prediction, environmental, sociopolitical 


\section{INTRODUCTION}

Hydroelectric power is currently the largest of the renewable energy resources worldwide, contributing to electricity generation in 160 countries (Manzano-Agugliaro et al., 2013). The environmental impacts of hydropower are well established (Liermann et al., 2012; Nilsson et al., 2005; Poff et al., 1997; Poff et al., 2007), and are mitigated with mixed success (Trussart et al., 2002). In the United States (U.S.), the authority to issue 30-50 year licenses for the operation of non-federal hydropower facilities belongs to the U.S. Federal Energy Regulatory Commission (FERC). The passage of the Electric Consumers Protection Act of 1986 (ECPA) substantially changed FERC's consideration of environmental impacts with the requirement that equal consideration be given to the protection and enhancement of, and mitigation of damage to, wildlife, environmental quality, and recreational opportunity. Furthermore, a string of court rulings eroded FERC's singular authority to prescribe environmental mitigation by requiring FERC to include fishway prescriptions from the National Marine Fisheries Service or U.S. Fish and Wildlife Service, as well as minimum streamflow requirements included as part of state water quality certificates (Blumm and Nadol, 2001; Tarlock, 2012). The result was a significant increase in the number of mitigation requirements included in FERC licenses and a growing role of other federal and state agencies in the licensing process (Blumm and Nadol, 2001; Deshazo and Freeman, 2005; Kosnik, 2010).

FERC and the hydropower industry have suggested that this instable policy context and increased regulatory plurality have resulted in increased licensing time and increased uncertainty in mitigation requirements (FERC, 2001; U.S.-Congress, 2012). Original licenses for new projects and relicensing of existing projects provide a once in every 30 to 50 year opportunity to address environmental concerns at hydropower projects. FERC addresses potential environmental impacts by incorporating license conditions (mitigation requirements) where evidence shows project operations will impact environmental or recreational resources. With over 300 relicense applications anticipated between 2016 and 2026 (FERC, 2015), there is new urgency to integrate sustainability practices into future hydropower 
development by evaluating and balancing the environmental and social costs of hydropower projects with the variety of potential benefits hydropower projects provide.

Hydropower developers and owners desire some certainty and ability to better anticipate mitigation requirements. Similarly, resource managers and regulators must be able to evaluate likely mitigation scenarios and determine the relative effectiveness of mitigation implemented at similar projects. While each hydropower project is unique, $\mathrm{Yu}$ and $\mathrm{Xu}$ (2016) recommend development of common approaches and principles for designing ecological and social compensation mechanisms for hydropower development. The authors of this manuscript recently developed a database of environmental mitigation requirements in FERC licenses (Schramm et al., 2016) that presents new opportunities for analyzing past environmental mitigation requirements and predicting future mitigation requirements.

In this study we sought to examine the feasibility of using a suite of multidisciplinary explanatory variables to fit predictive models for environmental mitigation requirements at hydropower projects across the conterminous U.S. We developed a spatially explicit framework (applying niche modeling concepts common in landscape ecology) to predict nearly 50 types of environmental mitigation requirements using biological, facility, human, hydrologic, landscape, locational, and stream network characteristics. Our primary goal was to build statistical models to predict future mitigation requirements at hydropower project sites, while the secondary goal was to gain some understanding into potential key

environmental and social drivers of these requirements that may warrant additional future research. As an example of how the models can be applied, we made predictions to a set of non-powered dams (NPDs) across the U.S. that were previously identified as having considerable energy potential.

\section{MATERIALS AND METHODS}

The conterminous United States (Fig. 1) is environmentally and culturally heterogeneous (Fig. 2), containing diverse physiographic regions ranging from mountains to inland and coastal plains, and 
encompassing examples of nearly every global climate. There is also considerable geographic variation in socio-political, economic, and cultural characteristics.

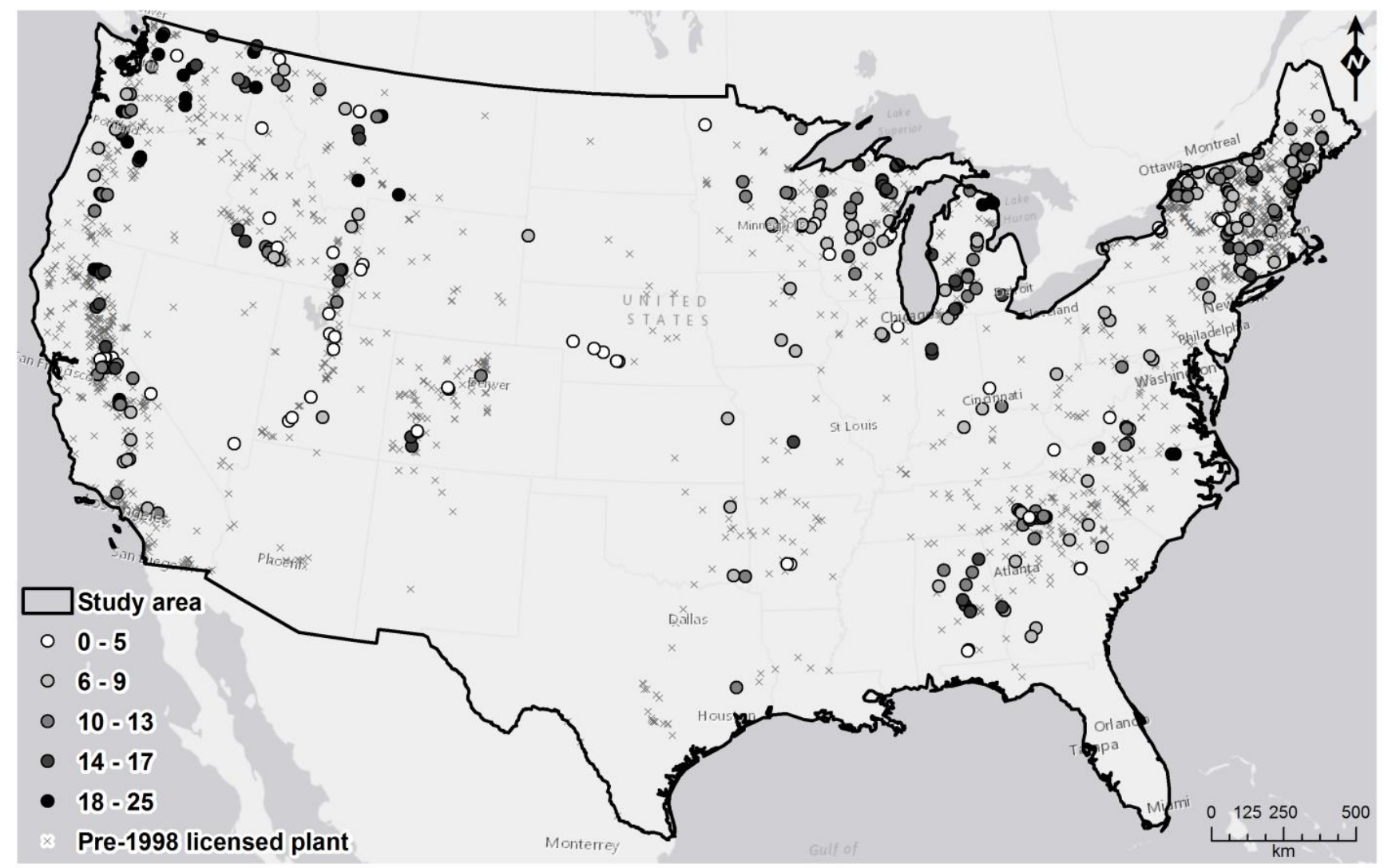

Fig. 1. Study area showing location of 463 hydropower plants licensed from 1998 through September 2015. Color of plant locations indicates number of mitigation requirements for mitigation categories selected for statistical modeling. 

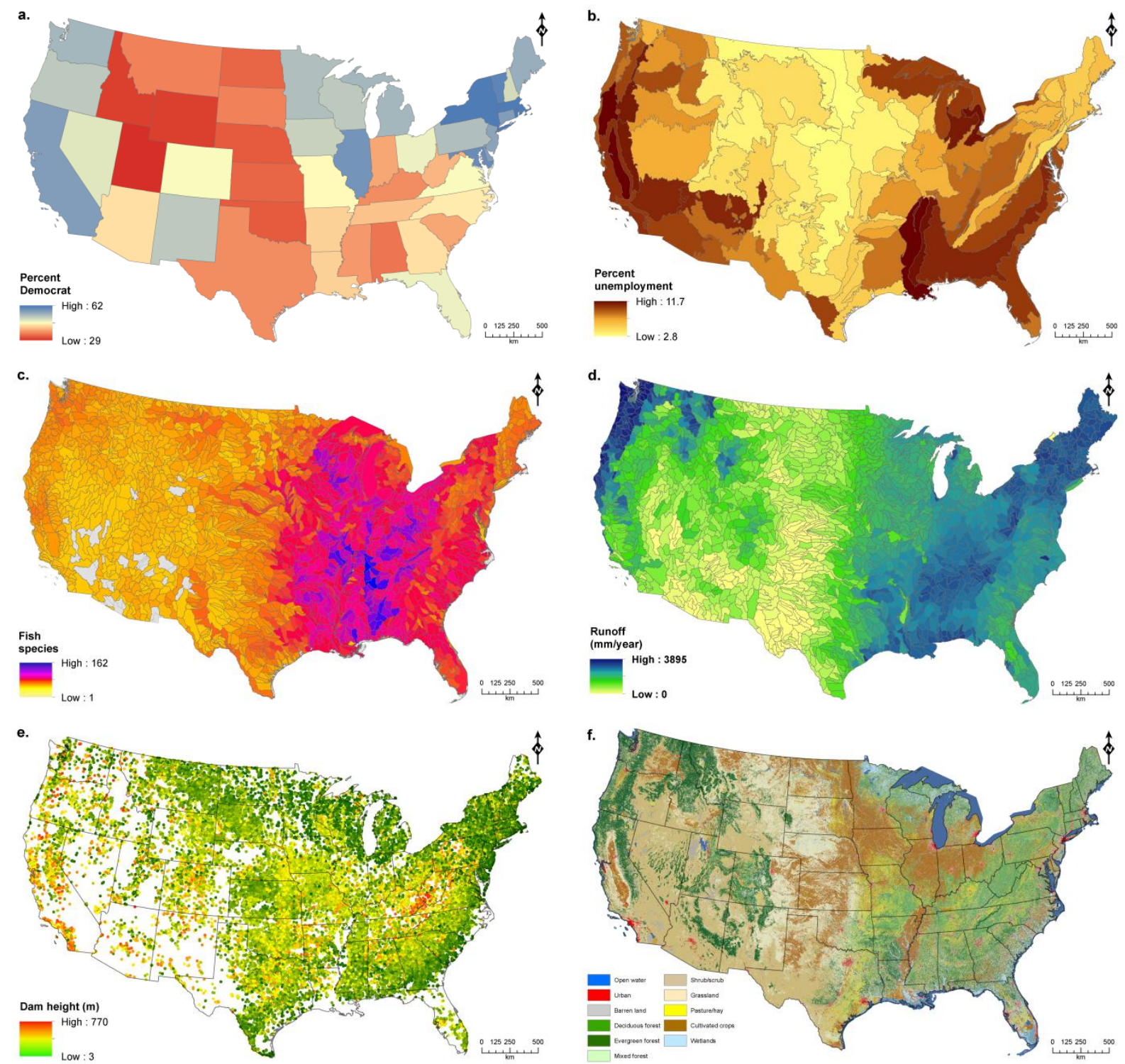

Fig. 2. a. Average percent democratic votes cast in U.S. presidential elections from 1996 to 2012 . b. Percent unemployment from 2010 U.S. census, aggregated to physiographic region. c. Number of freshwater fish species per HUC8 watershed. d. Average annual runoff per HUC8 watershed. e. Dam locations symbolized by height. f. 2011 land cover.

\subsection{Mitigation database and response variables}

A database of environmental mitigation requirements was compiled for FERC licenses issued from 1998 through September 2015 (Schramm et al., 2016). Since our goal is prediction of future mitigation requirements, the manual review of licenses was limited to those issued from 1998 through 2015 with an assumption that more recently issued licenses would better reflect future mitigation requirements. The database includes Bernoulli distributed presence-absence mitigation data at 463 hydropower plants in the 
study area from 316 licenses. Six broad categories (Tier 1) of mitigation (biodiversity, fish passage, habitat, hydrology, recreation, and water quality) and 20 subcategories (Tier 2) were used to classify specific mitigation types in the hierarchical database. A full list of each of the mitigation types catalogued in the database and the percent of times each was required, including each of the 132 Tier 3 categories, is presented in Appendix A. Descriptions of each of the Tier 3 categories is provided in Appendix A of Schramm et al. (2016). Predictive models were built only if a mitigation type was required for at least 5\% (Rickbeil et al., 2014) of the plants in the mitigation database. Models were not built for the very broad Tier 1 categories.

\subsection{Explanatory variables}

Given that hydropower project licensing is influenced by a suite of biophysical and socio-economic factors, the candidate predictor variables (Table 1) employed here were selected based on expert opinion and on previous research by Kosnik (2010) and Trussart (2002) as broad-scale measures of biological, facility, human, hydrologic, landscape, locational, and stream network characteristics thought to have some bearing on mitigation requirements. The models that each candidate predictor was included in are indicated in Table 1. We used expert opinion to identify candidate predictors for each of the six Tier 1 categories, and these six predictor sets were then used to build models for each Tier 2 and Tier 3 model nested within the Tier I categories. Given that our goal was prediction and not explanation, we did not delve into the exact causal role of each potential predictor. Instead, we selected predictors based on hypothesized quality of association between the predictor and the response, data quality, and data availability (Shmueli, 2010).

\subsubsection{Biological}

The presence or absence of important fish species can influence not only fish passage mitigation requirements but also other measures related to biological conservation (Cada, 1998; Fraley et al., 1989; Renofalt et al., 2010). We used conservation status in concert with expert opinion to compile a list of 
high profile migratory fish species supported by policy protections (McManamay et al., 2015). We then mapped distributions of each of these species using the NatureServe (2010) database of current 
Table 1. Summary and description of input variables for the boosted regression tree models. Variables or units in bold and underlined indicate remaining predictor variables after collinearity analysis.

\begin{tabular}{|c|c|c|c|c|c|}
\hline Variable & Description & Units & Spatial scale & Source & Models \\
\hline \multicolumn{6}{|c|}{ Biological } \\
\hline bigPlyrSum & Major migratory fish species & Count & HUC8 watershed & NatureServe fish distributions, expert opinion & $\mathrm{P}, \mathrm{H}, \mathrm{B}, \mathrm{A}, \mathrm{R}$ \\
\hline \multicolumn{6}{|c|}{ Facility } \\
\hline Height & Dam height & Feet & Hydropower dam & ORNL NHAAP database & $\mathrm{P}, \mathrm{H}, \mathrm{W}, \mathrm{B}, \mathrm{A}, \mathrm{R}$ \\
\hline HY_MW & Generation capacity & Megawatts & Hydropower dam & ORNL NHAAP database & -- \\
\hline HY_MWh & Generation & Megawatt-hours & Hydropower plant & ORNL NHAAP database & -- \\
\hline Length & Dam length & Feet & Hydropower dam & ORNL NHAAP database & $\mathrm{P}, \mathrm{H}, \mathrm{W}, \mathrm{B}, \mathrm{A}, \mathrm{R}$ \\
\hline Mode & Dam mode-of-operation & Categorical & Hydropower dam & ORNL NHAAP database & $\mathrm{P}, \mathrm{H}, \mathrm{W}, \mathrm{B}, \mathrm{A}, \mathrm{R}$ \\
\hline$\overline{\text { owner }}$ & Ownership type & Categorical & Hydropower dam & ORNL NHAAP database & $\mathrm{P}, \mathrm{H}, \mathrm{W}, \mathrm{B}, \mathrm{A}, \mathrm{R}$ \\
\hline PrmyPurps & Dam primary purpose & Categorical & Hydropower dam & ORNL NHAAP database & $\mathrm{P}, \mathrm{H}, \mathrm{W}, \mathrm{B}, \mathrm{A}, \mathrm{R}$ \\
\hline \multicolumn{6}{|c|}{ Human } \\
\hline birdG_xx & National Audubon Society chapters & Count, PA, PC & State & National Audubon Society & -- \\
\hline damR_xx & Dam removals & Count, PA, PC & State & American Rivers & $\mathrm{P}, \mathrm{H}, \mathrm{W}, \mathrm{B}, \mathrm{A}, \mathrm{R}$ \\
\hline education & Education attainment - percent bachelor's degree or higher & Percent & USEPA Level 3 Ecoregion & US Census & $\mathrm{P}, \mathrm{H}, \mathrm{W}, \mathrm{B}, \mathrm{A}, \mathrm{R}$ \\
\hline FishG_xx & TU and CCA chapters & $\underline{\text { Count, }}$, PA, PC & State & TU, CCA & $\mathrm{P}, \mathrm{H}, \mathrm{B}, \mathrm{A}, \mathrm{R}$ \\
\hline$\overline{\text { hshldincm }}$ & Mean household income & $\overline{\text { US dollars }}$ & USEPA Level 3 Ecoregion & US Census & -- \\
\hline Issue Year & FERC hydropower project license issue year & Year & Hydropower plant & ORNL NHAAP database & $\mathrm{P}, \mathrm{H}, \mathrm{W}, \mathrm{B}, \mathrm{A}, \mathrm{R}$ \\
\hline LandG_xx & Land trusts & Count, PA, PC & State & Land Trust Alliance & -- \\
\hline politics & see note* & Difference & State & US Federal Election Commission & $\mathrm{P}, \mathrm{H}, \mathrm{W}, \mathrm{B}, \mathrm{A}, \mathrm{R}$ \\
\hline XX_POPDENS & 2000 population density & Individuals/km2 ( $\mathrm{L}$ and $\mathrm{N})$ & NHD Plus V1 Catchment & National Fish Habitat Partnership & $\mathrm{H}, \mathrm{W}, \mathrm{B}, \mathrm{A}, \mathrm{R}$ \\
\hline q12_avg & Survey response on environmental impact of dams & Rank & Geographic region & MIT Energy Survey, 2008 & $\mathrm{P}, \mathrm{H}, \mathrm{W}, \mathrm{B}, \mathrm{A}, \mathrm{R}$ \\
\hline q16_avg & Survey response on increasing or decreasing hydro power & Rank & Geographic region & MIT Energy Survey, 2008 & $\mathrm{P}, \mathrm{H}, \mathrm{W}, \mathrm{B}, \mathrm{A}, \mathrm{R}$ \\
\hline SierG_xx & Sierra Club chapters & Count, $\underline{\mathbf{P A}}, \underline{\mathbf{P C}}$ & State & Sierra Club & $\mathrm{P}, \mathrm{H}, \mathrm{W}, \mathrm{B}, \mathrm{A}, \mathrm{R}$ \\
\hline unemplymnt & Unemployment & Percent & USEPA Level 3 Ecoregion & US Census & $\mathrm{P}, \mathrm{H}, \mathrm{W}, \mathrm{B}, \mathrm{A}, \mathrm{R}$ \\
\hline usHouse & LCV US House of Rep. mean scorecard for 1998 to 2013 & Percent & State & League of Conservation Voters & -- \\
\hline usSenate & LCV US Senate mean scorecard for 1998 to 2013 & Percent & State & League of Conservation Voters & -- \\
\hline wshed_xx & Local watershed associations & Count, PA, PC & State & USEPA & $\mathrm{P}, \mathrm{H}, \mathrm{W}, \mathrm{B}, \mathrm{A}, \mathrm{R}$ \\
\hline \multicolumn{6}{|c|}{ Hydrology } \\
\hline$\underline{\text { ADRAIN }}$ & Total artificial drainage area & Square meters & NHD Plus V1 Catchment & USGS & $\mathrm{H}, \mathrm{W}, \mathrm{A}$ \\
\hline BFI_MEAN & Mean base-flow index for GW discharge into streams & Percent & NHD Plus V1 Catchment & USGS & $\mathrm{H}, \mathrm{W}, \mathrm{A}$ \\
\hline CNTC_MEAN & Baseflow residence time in the subsurface & Days & NHD Plus V1 Catchment & USGS & $\mathrm{H}, \mathrm{W}, \mathrm{A}$ \\
\hline$\overline{\text { DITCHES }}$ & Estimated area subject to the practice of ditches & Square meters & NHD Plus V1 Catchment & USGS & -- \\
\hline FlowYr & Average annual flow & Cubic feet per second & NHD Plus V1 Flowline & NHD Plus V1 & $\mathrm{P}, \mathrm{H}, \mathrm{W}, \mathrm{B}, \mathrm{A}, \mathrm{R}$ \\
\hline$\overline{\text { IRRIG }}$ & Estimated area subject to the practice of irrigation & Square meters & NHD Plus V1 Catchment & USGS & -- \\
\hline KFACT & Soil erodibility factor & Dimensionless & NHD Plus V1 Catchment & USGS & $\mathrm{H}, \mathrm{W}, \mathrm{A}$ \\
\hline$\overline{\text { MAVELU }}$ & Mean Annual Velocity (fps) at bottom of flowline & Cubic feet per second & NHD Plus V1 Flowline & NHD Plus V1 & $\mathrm{P}, \mathrm{H}, \mathrm{W}, \mathrm{B}, \mathrm{A}, \mathrm{R}$ \\
\hline MEAN_IEOF & Mean value for infiltration-excess overland flow & Percent & NHD Plus V1 Catchment & USGS & $\mathrm{H}, \mathrm{W}, \mathrm{A}$ \\
\hline$\overline{\text { MEAN_RCHRG }}$ & Mean annual natural groundwater recharge & Millimeters & NHD Plus V1 Catchment & USGS & -- \\
\hline nidStorSum & Accumulated upstream storage & Acre-feet & Hydropower dam & National Anthropogenic Barriers Dataset & $\mathrm{H}, \mathrm{W}, \mathrm{A}$ \\
\hline$\overline{\text { ResDay }}$ & Reservoir residence time & Days & Hydropower dam & ORNL NHAAP database & $\mathrm{P}, \mathrm{H}, \mathrm{W}, \mathrm{B}, \mathrm{A}, \mathrm{R}$ \\
\hline SATOF_MEAN & Average value of saturation overland flow & Percent & NHD Plus V1 Catchment & USGS & $\mathrm{H}, \mathrm{W}, \mathrm{A}$ \\
\hline SfArea & Reservoir surface area & Acres & Hydropower dam & National Inventory of Dams & $\mathrm{P}, \mathrm{H}, \mathrm{W}, \mathrm{B}, \mathrm{A}, \mathrm{R}$ \\
\hline Stor & Reservoir storage & Acre-feet & Hydropower dam & National Inventory of Dams & -- \\
\hline TILES & Estimated area of tile drains & Square meters & NHD Plus V1 Catchment & USGS & -- \\
\hline \multicolumn{6}{|c|}{ Landscape } \\
\hline$\underline{\mathrm{xx} \_ \text {CROPS }}$ & Land cover classified as cultivated crops & Percent $(\mathbf{L}$ and $\mathbf{N})$ & NHD Plus V1 Catchment & National Fish Habitat Partnership & $\mathrm{H}, \mathrm{W}, \mathrm{B}, \mathrm{A}$ \\
\hline$\overline{\mathrm{xx} \text { NPDES }}$ & Number of NPDES sites & Count $(\underline{\mathbf{L} \text { and } N)}$ & NHD Plus V1 Catchment & National Fish Habitat Partnership & $\mathrm{H}, \mathrm{W}$ \\
\hline Xx_PASTURE & Land cover classified as pasture/hay & Percent $(\mathbf{L}$ and $\mathbf{N})$ & NHD Plus V1 Catchment & National Fish Habitat Partnership & $\mathrm{H}, \mathrm{W}, \mathrm{B}, \mathrm{A}$ \\
\hline xx_ROADCRC & Road-stream crossings & Count $(\mathrm{L}$ and $\mathrm{N})$ & NHD Plus V1 Catchment & USGS, National Fish Habitat Partnership & -- \\
\hline xx_URBANHC & Land cover classified as high intensity urban & Percent ( $\mathrm{L}$ and $\mathrm{N})$ & NHD Plus V1 Catchment & National Fish Habitat Partnership & -- \\
\hline XX_URBANL & Land cover classified as low intensity urban & Percent $(\mathbf{L}$ and $\mathbf{N})$ & NHD Plus V1 Catchment & National Fish Habitat Partnership & $\mathrm{H}, \mathrm{W}, \mathrm{B}, \mathrm{A}$ \\
\hline$\underline{\mathrm{xx} \text { URBANM }}$ & Land cover classified as medium intensity urban & Percent $(\underline{\mathbf{L}}$ and $\mathbf{N})$ & NHD Plus V1 Catchment & National Fish Habitat Partnership & $\mathrm{H}, \mathrm{W}, \mathrm{B}, \mathrm{A}$ \\
\hline$\overline{\text { CNPY_MEAN }}$ & Mean canopy cover & Percent & NHD Plus V1 Catchment & USGS & $\mathrm{H}, \mathrm{W}, \mathrm{B}, \mathrm{A}$ \\
\hline$\overline{\text { CROP_AREA }}$ & Total crop area for fertilizer/manure derived from land use & Square meters & NHD Plus V1 Catchment & USGS & $\mathrm{H}, \mathrm{W}, \mathrm{B}, \mathrm{A}$ \\
\hline d303_count & Impaired or threatened waters & Count & NHD Plus V1 Catchment & USEPA 303(d) list & $\mathrm{H}, \mathrm{W}, \mathrm{B}, \mathrm{A}$ \\
\hline IMPV_MEAN & Mean impervious surface & Percent & NHD Plus V1 Catchment & USGS & -- \\
\hline L_MINES & Number of mines or mineral processing plants & Count & NHD Plus V1 Catchment & National Fish Habitat Partnership & W \\
\hline L_ROADLEN & Length of roads & Meters & NHD Plus V1 Catchment & National Fish Habitat Partnership & $\mathrm{P}, \mathrm{H}, \mathrm{W}, \mathrm{B}, \mathrm{A}$ \\
\hline MAXELEVSMO & Maximum elevation & Meters & NHD Plus V1 Flowline & NHD Plus V1 & $\mathrm{P}, \mathrm{H}, \mathrm{W}, \mathrm{B}, \mathrm{A}, \mathrm{R}$ \\
\hline PPT30MEAN & 30-year (1971-2000) average annual precipitation & Millimeters & NHD Plus V1 Catchment & USGS & $\mathrm{P}, \mathrm{H}, \mathrm{W}, \mathrm{B}, \mathrm{A}, \mathrm{R}$ \\
\hline SLOPE & Slope of stream reach & Unitless & NHD Plus V1 Flowline & NHD Plus V1 & $\mathrm{P}, \mathrm{H}, \mathrm{W}, \mathrm{B}, \mathrm{A}, \mathrm{R}$ \\
\hline$\overline{\text { SLP_PERC }}$ & Landscape slope & Percent & NHD Plus V1 Catchment & USGS & $\mathrm{P}, \mathrm{H}, \mathrm{W}, \mathrm{B}, \mathrm{A}, \mathrm{R}$ \\
\hline TMAX30_MEA & 30-year (1971-2000) average annual maximum temperature & Celsius & NHD Plus V1 Catchment & USGS & -- \\
\hline \multicolumn{6}{|c|}{ Location } \\
\hline POINT_X & Longitude & Decimal degrees & Hydropower dam & National Anthropogenic Barriers Dataset & $\mathrm{P}, \mathrm{H}, \mathrm{W}, \mathrm{B}, \mathrm{A}, \mathrm{R}$ \\
\hline$\overline{\text { POINT_Y }}$ & Latitude & Decimal degrees & Hydropower dam & National Anthropogenic Barriers Dataset & $\mathrm{P}, \mathrm{H}, \mathrm{W}, \mathrm{B}, \mathrm{A}, \mathrm{R}$ \\
\hline \multicolumn{6}{|c|}{ Stream network } \\
\hline dist2Mouth & Stream network distance to network mouth & Meters & Entire downstream flow path & Calculated from NHD Plus V1 flowlines & $\mathrm{P}, \mathrm{H}, \mathrm{W}, \mathrm{B}, \mathrm{A}, \mathrm{R}$ \\
\hline DrArea & Drainage area upstream of dam & Square miles & Hydropower dam & National Inventory of Dams & -- \\
\hline dsDams & Downstream dams on flow path to network mouth & Count & Entire downstream flow path & Calculated from NHD Plus V1 and NABD & $\mathrm{P}, \mathrm{H}, \mathrm{W}, \mathrm{B}, \mathrm{A}, \mathrm{R}$ \\
\hline$\overline{\text { N_DAMSC }}$ & Number of dams within network catchment & Count & NHD Plus V1 Catchment & National Fish Habitat Partnership & $\mathrm{P}, \mathrm{H}, \mathrm{W}, \mathrm{B}, \mathrm{A}, \mathrm{R}$ \\
\hline$\underline{\underline{\text { SO }}}$ & Strahler stream order & Strahler number & NHD Plus V1 Flowline & NHD Plus V1 & $\mathrm{P}, \mathrm{H}, \mathrm{W}, \mathrm{B}, \mathrm{A}, \mathrm{R}$ \\
\hline
\end{tabular}

$\mathrm{PA}=$ per area $\mathrm{PC}=$ per capita $\mathrm{L}=$ local catchment $\mathrm{N}=$ entire network catchment; $\mathrm{xx}$ indicates variable derived for multiple units; $\mathrm{P}=$ fish passage; $\mathrm{H}=$ hydrology; $\mathrm{W}=$ water quality; $\mathrm{B}=$ biodiversity; A = habitat; R = recreation; *politics is the difference between mean percent democrat and republican from 1996 to 2012 presidential elections; LCV = League of Conservation Voters; TU = Trout

Unlimited; $\mathrm{CCA}=$ Coastal Conservation Association. 
distributions of freshwater fishes of the U.S. at the 8-digit hydrologic unit code (HUC8) scale to allow for analysis of interactions between these high profile species and hydropower project locations. The biological explanatory variable is a count of the number of key fish species per HUC8 (McManamay et al., 2015).

\subsubsection{Facility characteristics}

The Oak Ridge National Laboratory (ORNL) National Hydropower Asset Assessment Program (NHAAP) is an integrated energy, water, and ecosystem research effort for sustainable hydroelectricity generation and water management. The ORNL NHAAP database (http://nhaap.ornl.gov/) integrates data from multiple data sources and provides the most current, detailed, and spatially comprehensive information for analyzing and visualizing existing U.S. hydropower assets. We included hydropower facility characteristics from the NHAAP database thought to be important drivers of prescribed mitigation such as dam height, generation capacity, dam mode-of-operation, and geographic location (Kosnik, 2010).

\subsubsection{Human dimensions}

The convergence of different anthropogenic characteristics such as presence of environmental interest groups, political climate, population demographics, and regulatory tendencies can be impactful on mitigation requirements (Kosnik, 2010). Consistent with the interest group theory of regulation (Peltzman, 1976), Knittel (2006) concluded that electricity industry regulators respond to lobbying from interest groups. In research focused on explaining drivers of environmental mitigation requirements at hydropower projects, Kosnik (2010) found the largest influences on FERC's regulatory decisions to be congressional politics and regulatory tendencies. In an attempt to capture the socio-political and regulatory landscape, we included numerous anthropogenic predictors that serve as direct measures or proxies for local, state, or regional political tendencies, environmental awareness, regulatory trends, and public attitudes toward dams. Candidate predictors aimed at capturing political tendencies include presidential election voting averaged over time and congressional politics. Different aspects of environmental awareness were estimated at a state-scale using prevalence of non-profit organizations, 
including protection of birds and their habitats (using National Audubon Society chapters), fish and their habitats (using Trout Unlimited chapters for freshwater and Coastal Conservation Association chapters for marine), land conservation (using land trusts), water quality conservation (using local watershed associations), and general environmental awareness (using Sierra Club chapters). Regulatory trends were estimated using the issue year of the license. Prevalence of dam removals and citizen survey responses on energy and environmental impacts from dams were used as estimates of public attitudes toward dams.

\subsubsection{Hydrology}

Operation of a hydropower facility typically involves modifications to hydrologic regimes both upstream and downstream of dams, reservoirs, or river diversions (Fraley et al., 1989; Ligon et al., 1995; Poff et al., 1997). The magnitude of these flow disturbances can be minimized by discharge management, and there is increasing pressure from regulatory agencies to incorporate ecological flow requirements in licenses and operational plans for hydropower projects (Bunn and Arthington, 2002; Renofalt et al., 2010; Trussart et al., 2002). We included a suite of explanatory variables derived at the stream reach and watershed scale that describe different aspects of the hydrologic regime of a given area, including surface water, groundwater, and reservoir storage characteristics.

\subsubsection{Landscape}

Broad-scale landscape descriptors such as land cover, terrain, and climate can influence prescribed mitigation in all six of the Tier 1 mitigation categories, either directly or indirectly. Thus we included numerous land cover metrics derived at multiple scales (Tong and Chen, 2002; Wang et al., 2001), topographic variables such as slope and elevation (Moore et al., 1991), and the core climatic variables of average annual precipitation and air temperature (Grimm et al., 2008).

\subsubsection{Location}

In the U.S., there are tangible trends and patterns in environmental, economic, cultural, and social conditions from east to west and north to south. We included latitude and longitude to account for spatial 
effects and capture spatial patterns across the large study area that may be insufficiently represented in the other predictors (Fink et al., 2010; Oppel et al., 2012).

\subsubsection{Stream network}

Stream network position and the prevalence of upstream and downstream dams are important descriptors of network fragmentation/connectivity (Kuby et al., 2005). Where a hydropower project falls on the stream network in relation to other barriers and the network mouth can have a strong influence on the nature and magnitude of ordered mitigation (Fraley et al., 1989; Kosnik, 2010).

\subsection{Statistical analyses}

Model development was carried out in R version 3.2.2 (R-Core-Team). Boosted regression trees (a machine-learning technique) were used to develop the predictive models, as this method has been demonstrated to have high predictive performance with presence-absence response variables, allows for complex regression analyses of complex responses, and can handle continuous and categorical explanatory variables (Abram et al., 2015; Arganaraz et al., 2015; Elith et al., 2006; Elith et al., 2008). Before running the models, all predictor variables were assessed for collinearity using Pearson’s correlation coefficients $(r)$. When $r$ values exceeded 0.7 (Dormann et al., 2013), the variable deemed more functionally applicable to hydropower mitigation (Arganaraz et al., 2015; Rickbeil et al., 2014) or that was derived at a higher spatial resolution was retained (Table 1). The data were split into training $(80 \%)$ and validation (20\%) data using the caret package in R, which creates random splits within each class so that the overall class distribution is preserved as well as possible (Kuhn, 2008).

Given the novelty of the mitigation database, we were unable to obtain an independent validation dataset as recommended by Araujo and Guisan (2006). The optimal number of trees was determined using 10 -fold cross validation $(\mathrm{CV})$, with the bag fraction set to 0.5 and the learning rate set to 0.001 to ensure that each model had at least 1,000 trees (Elith et al., 2008). The area under the receiver-operating characteristic curve (ROC) calculated on the validation dataset was used to assess predictive performance. We implemented the ROC interpretation presented by Hosmer et al. (2013) where an ROC value of 0.7- 
0.8 is considered an acceptable prediction, $0.8-0.9$ is excellent, and $>0.9$ is outstanding. For a model to be deemed acceptable, both the internal CV ROC and the validation ROC had to be $\geq 0.7$. We generated partial dependence plots to examine the nature of the models and to interpret the effect of a variable on the response after accounting for the average effects of all other variables in the model (Elith et al., 2008). Spatial autocorrelation of model residuals was evaluated using Moran's I statistics (Dormann et al., 2007) calculated with the Spatial Autocorrelation tool in ArcGIS version 10.2.2 (ESRI).

\subsection{Example model application at non-powered dams}

While approximately 2,500 dams in the U.S. provide 78 gigawatts (GW) of conventional and $22 \mathrm{GW}$ of pumped-storage hydropower, there are hundreds of NPDs originally built for other purposes that may be retrofitted for hydropower to produce an additional $12 \mathrm{GW}$ of estimated renewable energy for the U.S (Hadjerioua et al., 2012). While many of the monetary costs and environmental impacts have already been incurred at these sites, our models can be used as a tool to assess potential environmental mitigation

requirements that may arise during the hydropower licensing process. As an example of how the modeling can be applied, we made predictions for each of the acceptable models to 568 NPDs estimated by Hadjerioua et al. (2012) to have $>1$ megawatt (MW) in potential capacity. We used the optimal threshold function in the R package SDMtools (VanDerWal et al., 2012) to identify the value on the ROC curve that is closest to a perfect model fit, and then we applied that value as the predicted present/absent threshold when making predictions to the NPDs.

\section{RESULTS}

\subsection{BRT models}

Predictive models were built only if a mitigation type was required for at least 5\% (Rickbeil et al., 2014) of the plants in the mitigation database, resulting in 57 Tier 3 mitigation types being modelled and all 20 of the Tier 2 mitigations being modelled (see Table 2 for modeling results). Eight of the 57 Tier 3 models were rejected due to either a CV ROC or validation ROC $<0.7$, leaving 49 Tier 3 models with at 
least an acceptable fit. All 20 of the Tier 2 models had an ROC $\geq 0.7$. Significant spatial autocorrelation of model residuals was detected in 4 of 20 Tier 2 models and 11 of 49 Tier 3 models. 
Table 2. Model results summary.

\begin{tabular}{|c|c|c|c|c|c|c|c|c|c|c|c|}
\hline Tier 1 & Tier 2 & Tier 3 & ModeIID & Trees & $\begin{array}{l}\text { CV } \\
\text { ROC }\end{array}$ & $\begin{array}{l}\text { V } \\
\text { ROC }\end{array}$ & OT & MI & Influential Variable 1 & Influential Variable 2 & Influential Variable 3 \\
\hline \multirow[t]{12}{*}{ Fish Passage } & DS & NA (see Tier 2 category) & F101 & 5550 & 0.867 & 0.916 & 0.36 & -0.165 & POINT_Y (13) & dist2Mouth (10.7) & FlowYr (8) \\
\hline & Fish Passage & DS Passage Plan Study Design & F101010 & 5300 & 0.892 & 0.829 & 0.30 & -0.309 & POINT_Y (11.1) & dist2Mouth (9.9) & MAXELEVSMO $(9.1)$ \\
\hline & US & NA (see Tier 2 category) & F102 & 5250 & 0.899 & 0.896 & 0.29 & -0.436 & MAXELEVSMO (14.5) & POINT_Y (13) & bigPlyrSum (8.3) \\
\hline & Fish Passage & Eelway & F102017 & 4350 & 0.956 & 0.966 & 0.33 & -1.178 & MAXELEVSMO (36.5) & POINT_X (11.9) & bigPlyrSum (7.7) \\
\hline & & US passage study plan or design & F102023 & 5000 & 0.909 & 0.854 & 0.29 & -0.703 & MAXELEVSMO (12.3) & POINT_X $(10.5)$ & POINT_Y $(9.7)$ \\
\hline & Passage & NA (see Tier 2 category) & F103 & 2850 & 0.780 & 0.856 & 0.27 & -0.467 & POINT_Y (9.3) & dsDams (8.1) & MAXELEVSMO (7.5) \\
\hline & Planning & DS fish passage mon. sampling & F103029 & 3200 & 0.888 & 0.924 & 0.22 & -0.908 & MAXELEVSMO (18.2) & Height (10) & POINT_X (8.9) \\
\hline & & Fish passage \& operations plan & F103031 & 1050 & 0.739 & 0.749 & 0.08 & -0.246 & wshed_PC (11.8) & L_ROADLEN (10.5) & dsDams (9.9) \\
\hline & & Fish stranding plan mon. evaluation & F103033 & 1100 & 0.712 & 0.605 & -- & & -- & -- & -- \\
\hline & & US fish passage mon. sampling & F103036 & 3050 & 0.891 & 0.865 & 0.18 & -0.504 & MAXELEVSMO (16.2) & Height (11.9) & POINT_Y (8.7) \\
\hline & Entrainment & NA (see Tier 2 category) & F104 & 3450 & 0.849 & 0.756 & 0.29 & -0.222 & ResDay (9.8) & SierG_PC (7.8) & politics (7) \\
\hline & & Trash or bar rack & F104043 & 3700 & 0.917 & 0.833 & 0.22 & 0.147 & POINT_X (10.4) & SierG_PC $(9.6)$ & fishGroups (8.8) \\
\hline \multirow[t]{23}{*}{ Hydrology } & Flow & NA (see Tier 2 category) & F205 & 4700 & 0.785 & 0.787 & 0.56 & -1.413 & PrmryPurps (7.7) & N_URBANLC (5.3) & Height (5.1) \\
\hline & Mitigation & Tailrace flow mon. plan & F205045 & 5850 & 0.822 & 0.920 & 0.39 & -0.076 & POINT_X (8.5) & IssueYear (4.8) & politics (4.7) \\
\hline & & Tailrace flow or stage mon. equipment & F205048 & 2650 & 0.784 & 0.867 & 0.17 & -0.191 & N_CROPSC (9) & Length (7.3) & dist2Mouth (4.7) \\
\hline & & Tailrace ramping rate restriction & F205050 & 2400 & 0.790 & 0.834 & 0.19 & -0.333 & SfArea $(8.3)$ & CNPY_MEAN (5.9) & nidStorSum (5.8) \\
\hline & & Bypass flow mon. plan & F205052 & 2900 & 0.802 & 0.853 & 0.20 & -0.522 & politics (6.9) & Length (6.7) & SfArea (5.6) \\
\hline & & Bypass flushing or flood flow & F205054 & 3750 & 0.890 & 0.951 & 0.15 & 0.187 & POINT_X (24.6) & N_PASTUREC (6.8) & PPT30MEAN (6.2) \\
\hline & & Bypass flow or stage mon. equipment & F205055 & 1500 & 0.735 & 0.779 & 0.13 & -0.679 & SLP_PERC (18) & POINT_X (7) & bigPlyrSum (5.2) \\
\hline & & Bypass ramping rate restriction & F205057 & 2900 & 0.878 & 0.802 & 0.16 & 0.170 & POINT_X (28.6) & BFI_MEAN (6.7) & CNTC_MEAN (6.5) \\
\hline & Tairrace & NA (see Tier 2 category) & F206 & 3800 & 0.863 & 0.845 & 0.63 & -0.198 & POINT_X (10.4) & Mode (10.3) & SLP_PERC (7.2) \\
\hline & Minimum & Run-of-river Tailrace & F206058 & 3700 & 0.904 & 0.911 & 0.37 & -0.349 & Mode (39.2) & Height (7.8) & POINT_X (4.8) \\
\hline & Flow & Seasonal Tairrace & F206059 & 2700 & 0.850 & 0.846 & 0.20 & 0.087 & Mode (24.6) & POINT_Y (9.2) & N_PASTUREC (5.7) \\
\hline & & Year-round Tailrace & F206061 & 1500 & 0.787 & 0.899 & 0.19 & -0.312 & Mode (22.7) & owner (9.2) & Length (4.3) \\
\hline & Bypass & NA (see Tier 2 category) & F207 & 3250 & 0.808 & 0.771 & 0.46 & -0.676 & SfArea (16.3) & MAXELEVSMO (6.6) & MAVELU (4.7) \\
\hline & Minimum & Seasonal Bypass & F207063 & 1450 & 0.678 & 0.668 & -- & & -- & -- & -- \\
\hline & Flow & Year-round Bypass & F207065 & 1200 & 0.720 & 0.805 & 0.23 & -0.339 & SfArea (15.6) & Height (10.2) & Length (6.9) \\
\hline & Sediment & NA (see Tier 2 cates & F208 & 4850 & 0.767 & 0.851 & 0.49 & -0.364 & Issue Year (6.1) & CNPY_MEAN (5.3) & unemplymnt (4.6) \\
\hline & & Sediment \& erosio & F208066 & 4100 & 0.778 & 0.838 & 0.47 & -0.257 & Issue Year (6.6) & CNPY_MEAN (5) & dist2Mouth (4.9) \\
\hline & $\overline{\text { Recreation }}$ & NA (see Tier 2 category) & F209 & 1550 & 0.733 & 0.796 & 0.17 & -0.127 & POINT_X (12.3) & Height (6.8) & SierG_PA (6.8) \\
\hline & & Provide recreational flow releases & F209071 & 700 & 0.655 & 0.713 & -- & & -- & -- & -- \\
\hline & Operations & NA (see Tier 2 category) & F210 & 3050 & 0.734 & 0.819 & 0.53 & 0.040 & Flow Yr (8.6) & q16_avg (4.5) & N_URBANLC $(4$ \\
\hline & & Flow mg & F210073 & 3350 & 0.893 & 0.985 & 0.09 & -0.399 & Length (13) & wshedG_PA (11.4) & IssueYear (8.6) \\
\hline & & Operations complianc & F210074 & 5150 & 0.807 & 0.913 & 0.41 & 0.146 & politics $(8.8)$ & PrmryPurps (4.8) & FlowYr (4.7) \\
\hline & & Provide flow or lake levels electronically & F210075 & 1750 & 0.795 & 0.917 & 0.14 & -0.282 & SierG_PA (18.8) & POINT_X (6.2) & Mode (6.1) \\
\hline \multirow[t]{9}{*}{ Water Quality } & DS & NA (see Tier 2 category) & F311 & 4300 & 0.838 & 0.887 & 0.55 & -0.240 & ResDay (12.3) & SfArea $(6.8)$ & wshedG_PA (4.6) \\
\hline & Water & Benthic macroinvertebrate mon. & F311077 & 1500 & 0.724 & 0.938 & 0.12 & -0.396 & BFI_MEAN (16.9) & unemplymnt (8.3) & POINT_X (7.8) \\
\hline & Quality & DO enhancement or mitigation plan & F311078 & 2200 & 0.832 & 0.676 & -- & & -- & -- & -- \\
\hline & & Water quality mon. plan & F311086 & 6000 & 0.852 & 0.873 & 0.50 & -0.375 & ResDay (7.7) & SfArea (6.9) & Issue Year (5.1) \\
\hline & US & NA (see Tier 2 category) & $\mathrm{F} 312$ & 4000 & 0.831 & 0.860 & 0.23 & -0.320 & unemplymnt (7.6) & POINT_Y (6.8) & N_PASTUREC (6.8) \\
\hline & Water & mpling \& analysis & F312087 & 4500 & 0.965 & 0.823 & 0.39 & -1.704 & unemplymnt (13.4) & S_PA (9.7) & dist2Mouth (8.8) \\
\hline & Quality & Impoundment sediment analysis & F312088 & 4100 & 0.993 & 0.999 & 0.19 & 0.334 & wshedG_PA (21) & dist2Mouth (13.3) & unemplymnt (11.8) \\
\hline & & Inflow water quality mon. plan & F312090 & 1650 & 0.831 & 0.904 & 0.11 & 0.106 & wshedG_PA (12.1) & KFACT (9.3) & Length (6) \\
\hline & & Impoundment & F312091 & 4100 & 0.828 & 0.805 & 0.22 & -0.166 & N_PASTUREC (10) & unemplymnt (6.5) & CNTC_MEAN (5.6) \\
\hline \multirow[t]{10}{*}{ Biodiversity } & Terrestrial & NA (see Tier 2 category) & F413 & 4150 & 0.847 & 0.832 & 0.64 & -0.638 & POINT_X $(17.8)$ & SfArea $(8.7)$ & Height (6.4) \\
\hline & & Noxious we & F413094 & 6650 & 0.912 & 0.901 & 0.39 & 0.068 & POINT_X $(13.8)$ & IssueYear (10.4) & PPT30MEAN (6.2) \\
\hline & & Species conservation mgmt. $\mathrm{m}$ & F413095 & 5850 & 0.832 & 0.899 & 0.40 & -0.265 & damRmvls (8.9) & Length $(8.5)$ & Mode (6.7) \\
\hline & & T\&E sl & F413096 & 3950 & 0.879 & 0.905 & 0.21 & 0.965 & L_POPDENS (12.5) & SLP_PERC (6.8) & SfArea (5.8) \\
\hline & & Transmission related avian \& bat pr & F413097 & 6250 & 0.936 & 0.941 & 0.19 & -0.109 & PPT30MEAN (10.3) & POINT_X $(9.7)$ & dsDams (7.5) \\
\hline & & Wildlife ter & F413098 & 4100 & 0.844 & 0.937 & 0.27 & 0.146 & Flow $\mathrm{Yr}(6.3)$ & SfArea (5.6) & SierG_PC (5.2) \\
\hline & $\overline{\text { Aquatic }}$ & NA (see Tier 2 category) & F414 & 3500 & 0.791 & 0.859 & 0.35 & -0.271 & Flow Yr (11.1) & CNPY_MEAN (6.2) & PPT30MEAN (5.7) \\
\hline & & & F414100 & 3400 & 0.807 & 0.869 & 0.34 & -0.336 & Flow $Y r(7.9)$ & NT_X $(7.1)$ & dist2Mouth (5.4) \\
\hline & & Diadron & F414101 & 3000 & 0.871 & 0.901 & 0.26 & 0.124 & POINT_Y (22.1) & Flow $\operatorname{Yr}(11.2)$ & PPT30MEAN (8.4) \\
\hline & & Invasi & F414102 & 2800 & 0.800 & 0.881 & 0.19 & 0.552 & Flor & IS (6.4) & POINT_Y (6.2) \\
\hline Habitat & Fisheries & NA (see Tier 2 category) & F515 & 2650 & 0.776 & 0.730 & 0.27 & -0.038 & POINT_X (8.5) & PPT30MEAN (7.4) & Length (5.6) \\
\hline & & & F515105 & 1200 & 0.687 & 0.680 & -- & & -- & -- & -- \\
\hline & & DS woody debris restoration or passage & F515106 & 2850 & 0.863 & 0.879 & 0.25 & 0.071 & POINT_Y (7.3) & Length (6.2) & damRmvls (5.5) \\
\hline & Riparian & $\mathrm{NA}$ (see Ti & F516 & 2600 & 0.771 & 0.869 & 0.28 & 0.084 & L_POPDENS $(8$. & BFI_MEAN (7.8) & POINT_X (7.4) \\
\hline & & Establish riparian buffers & F516108 & 3100 & 0.866 & 0.864 & 0.25 & 0.673 & Mode (10) & IssueYear (9) & MAVELU (6.5) \\
\hline & & Riparian & F516110 & 2300 & 0.793 & 0.912 & 0.22 & -0.368 & L_POPDENS & (7.4) & T30MEAN (7) \\
\hline & Reservoir & NA (se & F517 & 6100 & 0.858 & 0.905 & 0.40 & -0.082 & ResDay (6.4) & Year (5.8) & fArea (5.4) \\
\hline & & Noxious & F517111 & 6950 & 0.928 & 0.952 & 0.25 & -0.348 & fishGroups (9.2) & Isst & Lengtl \\
\hline & & Shoreline mgmt. plan or program & F517112 & 4800 & 0.856 & 0.952 & 0.27 & 0.192 & POINT_Y (10.2) & SfArea (8.4) & Height (7.5) \\
\hline & Wetlands & NA (see & F518 & 3800 & 0.828 & 0.874 & 0.19 & 0.207 & SierG_PA & NT_Y $(10$. & L_POPDEN: \\
\hline & & Wetland protection & F518116 & 3500 & 0.878 & 0.875 & 0.14 & 0.082 & POINT_Y (12.4) & Mode (8.5) & PPT30MEAN (6.6) \\
\hline Recreation & Resources & NA (see Tier 2 category) & F619 & 3200 & 0.741 & 0.744 & 0.65 & 0.089 & SfArea (10.6) & Flow Yr (7.6) & Length (6.9) \\
\hline & & Boating facilities & F619118 & 1200 & 0.625 & 0.660 & -- & & -- & -- & -- \\
\hline & Mitigation & tage launch & F619119 & 5000 & 0.859 & 0.773 & 0.37 & -0.161 & POINT_X (10.2) & dsDams (8) & N_DAMSC (6.7) \\
\hline & & & F619120 & 1700 & 0.797 & 0.869 & 0.13 & 0.055 & N_DAMSC (18.3) & SfArea (10) & POINT_Y (8.2) \\
\hline & & Int & F619123 & 1900 & 0.720 & 0.731 & 0.20 & -0.192 & MAVELU (7.3) & PPT30MEAN & dist2Mouth (6.7) \\
\hline & & Parking & F619125 & 3550 & 0.715 & 0.722 & 0.32 & 0.441 & MAXELEVSMO (13) & Flow Yr (8.2) & ResDay (6.5) \\
\hline & & $\mathrm{Sh}$ & F619128 & 750 & 0.623 & 0.759 & -- & & -- & -- & -- \\
\hline & & $\mathrm{St}$ & F619129 & 1250 & 0.756 & 0.796 & 0.09 & 0.069 & Flow $Y r(14)$ & PPT30MEAN (9.8) & Height (9.7) \\
\hline & & $\operatorname{Tra}$ & F619130 & 3200 & 0.781 & 0.601 & -- & & -- & -- & -- \\
\hline & & Other day use area improvements & F619132 & 4900 & 0.750 & 0.781 & 0.44 & -0.430 & ResDay (8.5) & Issue Year (7.3) & PPT30MEAN (6.3) \\
\hline & ning & NA (see Tier 2 category) & F620 & 2450 & 0.753 & 0.883 & 0.74 & -0.001 & PrmryPurps (15.8) & SfArea (10.6) & Length $(9.6)$ \\
\hline & & Recreational mgmt. plan study or mon. & F620131 & 2450 & 0.753 & 0.883 & 0.74 & -0.001 & PrmryPurps (15.8) & SfArea (10.6) & Length (9.6) \\
\hline
\end{tabular}

See Table 1 for variable descriptions; if no influential variables are shown, model rejected due to poor fit; mgmt. = management; DS = downstream; US = upstream; T\&E = threatened and endangered, mon. = monitoring; $\mathrm{NA}=$ not applicable; $\mathrm{CV}$ ROC $=$ internal cross-validation ROC; V ROC = validation ROC; OT = optimal threshold; MI = Moran's Index; italics indicates spatial autocorrelation detected in training data; color scheme for influential variables corresponds to Table 1 color scheme. 


\subsection{Explanatory variables}

The three variables with the highest relative influence in each model are presented in Table 2, and partial dependence plots for these variables are presented in Appendix B. Overall, we considered a variable important if its relative influence was $\geq 5 \%$ (Parisien et al., 2011). A summary of the important variables for the Tier 3 models (Fig. 3) shows that nearly all the categories of variables (i.e. biological, facility, human, hydrologic, landscape, locational, and stream network) were influential within each Tier 1 category.

\begin{tabular}{|c|c|c|c|}
\hline \multicolumn{2}{|c|}{ Fish passage $(n=7)$} & \multicolumn{2}{|c|}{ Hydrology $(n=15)$} \\
\hline \begin{tabular}{|l|} 
Variable \\
\end{tabular} & F Inf & Variable & F Inf \\
\hline POINT_X & 70.63 & Mode & 50.79 \\
\hline MAXELEVSMO & 60.92 & POINT_X & 50.74 \\
\hline POINT_Y & 40.67 & Length & $\begin{array}{ll}4 & 0.81\end{array}$ \\
\hline bigPlyrSum & 40.41 & SfArea & 30.94 \\
\hline Height & 30.58 & nidStorSum & 30.64 \\
\hline dist2Mouth & 30.57 & Height & 30.45 \\
\hline dsDams & 20.74 & politics & 21.00 \\
\hline fishG_PC & 20.39 & IssueYear & 20.83 \\
\hline FlowYr & 20.33 & CNPY_MEAN & 20.73 \\
\hline wshed_PC & 11.00 & N_PASTUREC & 20.25 \\
\hline SierG_PC & 10.92 & unemplymnt & 20.22 \\
\hline L_ROADLEN & 10.89 & SierG_PA & $\begin{array}{ll}1 & 1.00\end{array}$ \\
\hline fishGroups & 10.84 & N_CROPSC & 11.00 \\
\hline politics & 10.74 & SLP_PERC & $\begin{array}{ll}1 & 1.00\end{array}$ \\
\hline PrmryPurps & 10.62 & wshedG_PA & 10.88 \\
\hline SfArea & 10.50 & fishG_PC & 10.63 \\
\hline SLOPE & 10.43 & owner & 10.40 \\
\hline MAVELU & 10.43 & POINT_Y & $\begin{array}{ll}10.37 \\
\end{array}$ \\
\hline & & FlowYr & $\begin{array}{ll}1 & 0.33 \\
-1\end{array}$ \\
\hline & & bigPlyrSum & $\begin{array}{ll}1 & 0.29\end{array}$ \\
\hline & & dist2Mouth & $\begin{array}{ll}1 & 0.29\end{array}$ \\
\hline & & PРT30MEAN & 10.25 \\
\hline & & BFI_MEAN & $\begin{array}{ll}1 & 0.24\end{array}$ \\
\hline & & CNTC_MEAN & $\begin{array}{ll}1 & 0.23\end{array}$ \\
\hline & & MAVELU & $\begin{array}{ll}1 & 0.21\end{array}$ \\
\hline & & SierG_PC & $\begin{array}{ll}1 & 0.19\end{array}$ \\
\hline
\end{tabular}

\begin{tabular}{|c|c|c|c|c|c|c|c|}
\hline \multicolumn{2}{|c|}{ Water quality $(n=7)$} & \multicolumn{2}{|c|}{ Biodiversity (n=8) } & \multicolumn{2}{|c|}{ Habitat $(n=6)$} & \multicolumn{2}{|c|}{ Recreation $(n=10)$} \\
\hline Variable & F Inf & Variable & F Inf & Variable & F Inf & Variable & F Inf \\
\hline unemplymnt & 40.68 & FlowYr & 40.88 & POINT_Y & 31.00 & FlowYr & 70.72 \\
\hline wshedG_PA & 30.91 & PPT30MEAN & 40.66 & Mode & 30.74 & PPT30MEAN & 60.72 \\
\hline BFI_MEAN & 30.61 & POINT_X & 30.95 & PPT30MEAN & 30.64 & ResDay & $\begin{array}{ll}5 & 0.59\end{array}$ \\
\hline dist2Mouth & 30.57 & SfArea & 30.57 & IssueYear & 20.86 & MAXELEVSMO & 40.80 \\
\hline SierG_PC & 30.41 & L_POPDENS & 20.71 & fishG_PC & 20.59 & Height & 40.66 \\
\hline SfArea & 20.87 & POINT_Y & 20.70 & L_POPDENS & 11.00 & Length & 40.66 \\
\hline IssueYear & 20.56 & SLP_PERC & 20.55 & fishGroups & 11.00 & dist2Mouth & 40.65 \\
\hline POINT_X & 20.44 & damRmvls & 11.00 & SierG_PA & 10.91 & SfArea & 40.56 \\
\hline N_PASTUREC & 11.00 & Length & 10.95 & Length & 10.85 & L_POPDENS & 30.73 \\
\hline N_DAMSC & 11.00 & SierG_PC & 10.82 & SfArea & 10.82 & dsDams & 30.54 \\
\hline ResDay & 11.00 & Mode & 10.75 & damRmvls & 10.75 & MAVELU & 20.84 \\
\hline KFACT & 10.76 & IssueYear & 10.75 & Height & 10.73 & N_DAMSC & 20.83 \\
\hline POINT_Y & 10.67 & dsDams & 10.73 & MAVELU & 10.65 & IssueYear & 20.77 \\
\hline CNTC_MEAN & 10.55 & PrmryPurps & 10.70 & education & 10.59 & SLOPE & 20.72 \\
\hline Length & 10.50 & dist2Mouth & 10.69 & wshedG_PA & 10.42 & POINT_X & 20.70 \\
\hline damRmvls & 10.44 & Height & 10.38 & PrmryPurps & 10.41 & POINT_Y & 20.54 \\
\hline Height & 10.35 & & & & & PrmryPurps & 11.00 \\
\hline & & & & & & unemplymnt & 10.48 \\
\hline & & & & & & Mode & 10.47 \\
\hline
\end{tabular}

Fig. 3. Explanatory variables with relative influence $\geqq 5$ for Tier 3 models, broken down by Tier 1 category. Relative influence normalized to 0 to 1 scale for each model; $\mathrm{Inf}=$ mean relative influence for variable across all models in which relative influence $\geqq 5 ; \mathrm{F}=$ frequency, or number of times variable had $\operatorname{Inf} \geqq 5$; color scheme corresponds to Table 1 .

Across all Tier 3 models (Fig. 4), the most important variables were longitude (location), reservoir surface area (hydrology), average annual flow (hydrology), precipitation (landscape), and latitude (location). Stream network, facility, human, and biological variables were also important but exceeded the $\geq 5 \%$ relative influence threshold less frequently. 


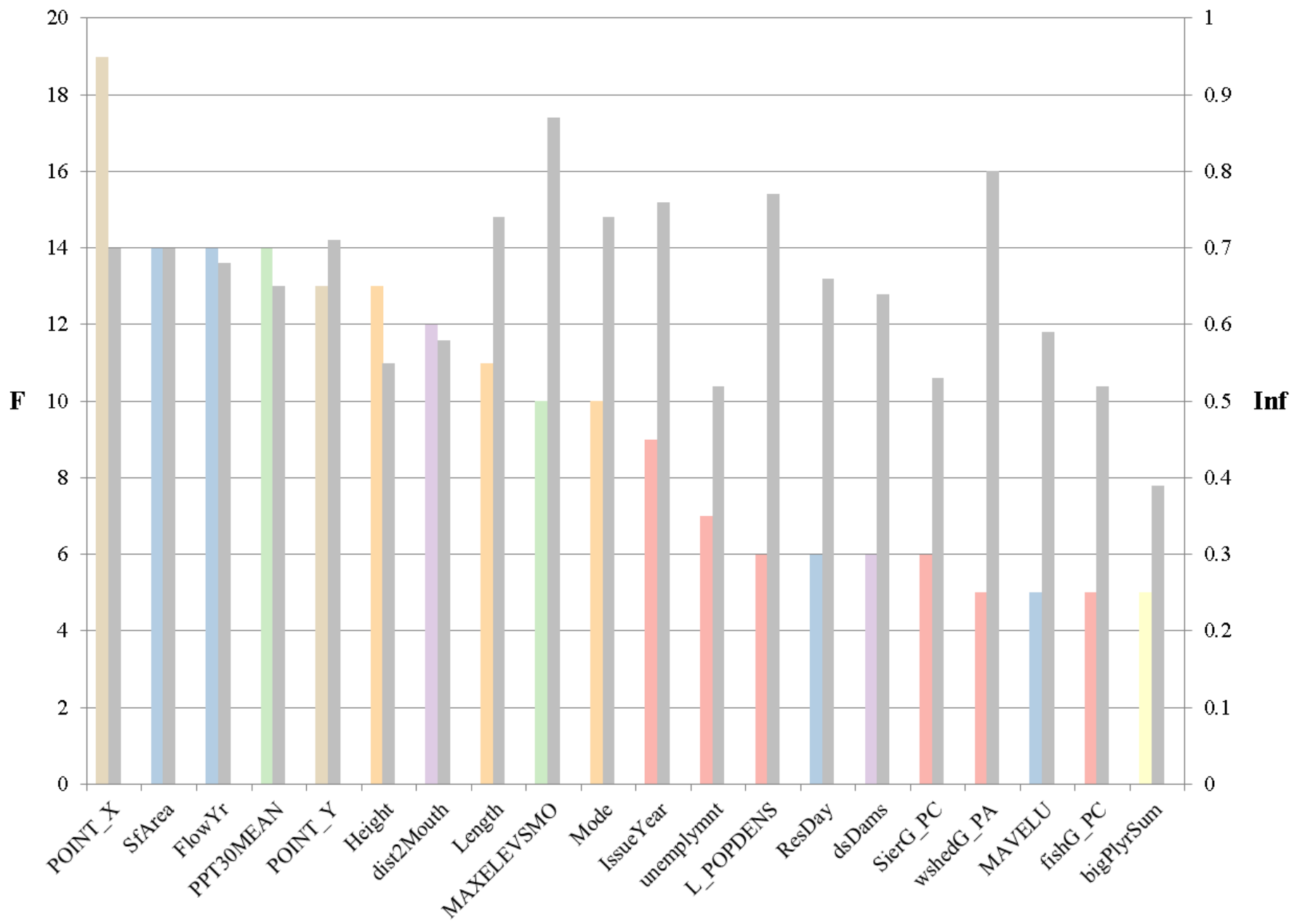

Fig. 4. The 20 most frequently occurring important variables across all Tier 3 models, sorted in descending order from left to right by frequency of occurrence. Colored bars present frequency, while grey bars present the normalized average relative influence for the variable across all of the models in which it was important.

To identify potential key environmental and social drivers of mitigation that may warrant additional future research, we examined important variables across all of our Tier 3 models based on frequency of importance and average relative influence. We grouped important variables into the potential future research areas of socio-political conditions, regional trends, network/landscape position, hydrology/site design, regulatory tendencies, and fisheries (Table 3). 
Table 3. The 20 most frequently occurring important variables across all Tier 3 models, with potential future research areas that correspond to each variable. $\mathrm{F}=$ frequency; $\mathrm{Inf}=$ normalized average relative influence.

\begin{tabular}{lllll} 
Variable & Category & F & Inf & Future research area \\
\hline POINT_X & Location & 19 & 0.70 & Regional trends \\
SfArea & Hydrology & 14 & 0.70 & Hydrology/site design \\
FlowYr & Hydrology & 14 & 0.68 & Hydrology/site design \\
PPT30MEAN & Landscape & 14 & 0.65 & Hydrology/site design \\
POINT_Y & Location & 13 & 0.71 & Regional trends \\
Height & Facility & 13 & 0.55 & Hydrology/site design \\
dist2Mouth & Stream network & 12 & 0.58 & Network/landscape position \\
\hline Length & Facility & 11 & 0.74 & Hydrology/site design \\
MAXELEVSMO & Landscape & 10 & 0.87 & Network/landscape position \\
Mode & Facility & 10 & 0.74 & Hydrology/site design \\
IssueYear & Human & 9 & 0.76 & Regulatory tendencies \\
\hline unemplymnt & Human & 7 & 0.52 & Socio-political conditions \\
\hline L_POPDENS & Human & 6 & 0.77 & Socio-political conditions \\
\hline ResDay & Hydrology & 6 & 0.66 & Hydrology/site design \\
\hline dsDams & Stream network & 6 & 0.64 & Network/landscape position \\
SierG_PC & Human & 6 & 0.53 & Socio-political conditions \\
\hline wshedG_PA & Human & 5 & 0.80 & Socio-political conditions \\
\hline MAVELU & Hydrology & 5 & 0.59 & Hydrology/site design \\
\hline fishG_PC & Human & 5 & 0.52 & Socio-political conditions \\
bigPlyrSum & Biological & 5 & 0.39 & Fisheries \\
\hline & & & &
\end{tabular}

\subsection{Predictions to NPDs}

We made predictions to 568 NPDs with > 1MW potential capacity for each of the 49 acceptable Tier 3 models (Fig. 5). The optimal present/absent threshold for each model is presented in Table 2. The number of predicted mitigation requirements ranged from 9 to 34 . 


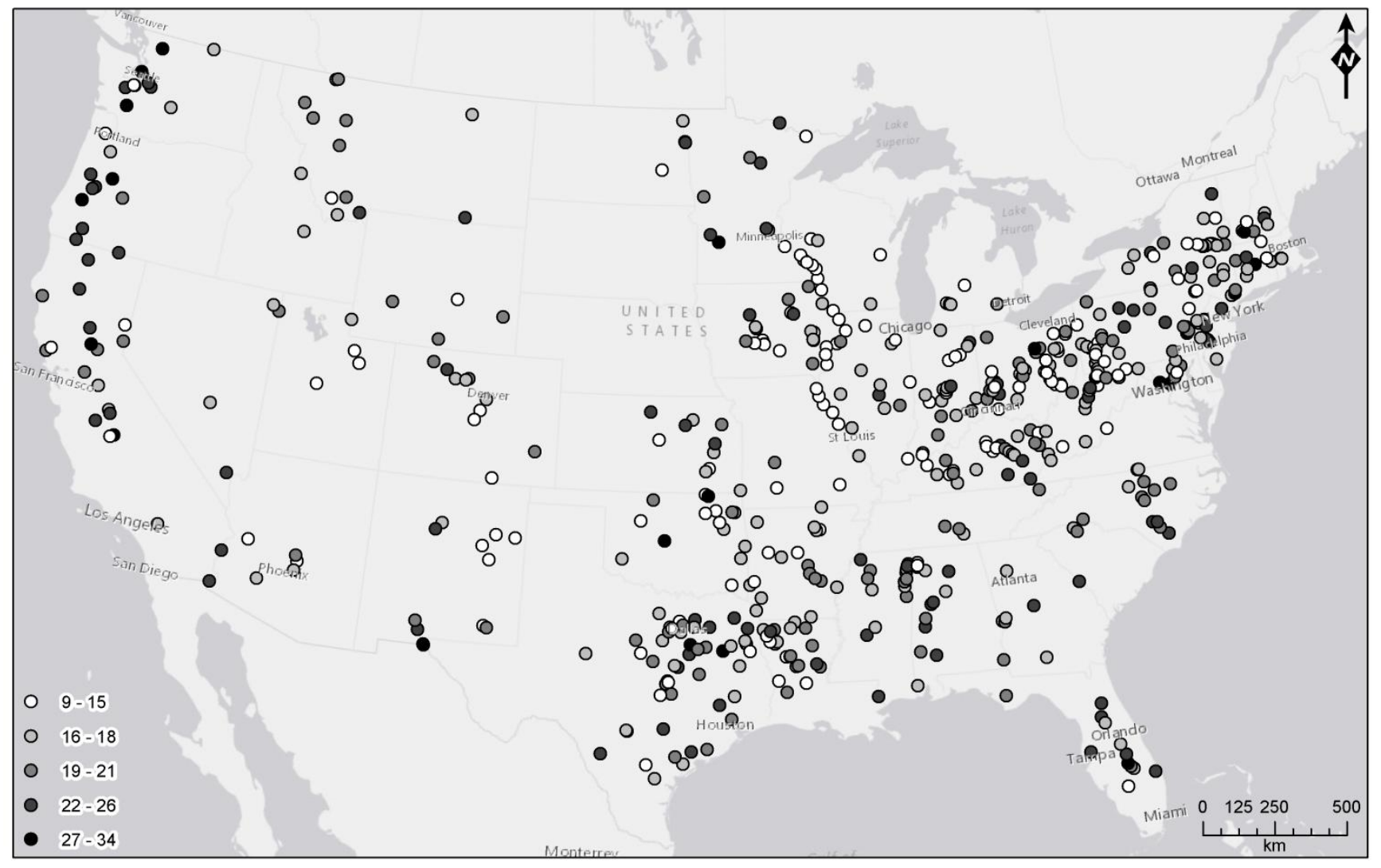

Fig. 5. Number of predicted Tier 3 mitigation requirements at NPDs with $>1 \mathrm{MW}$ energy potential.

\section{DISCUSSION}

The spatial modeling approach developed here integrates GIS techniques, novel data, machinelearning algorithms, and niche modeling concepts common in landscape ecology (see Guisan and Thuiller, 2005) to predict environmental mitigation requirements at hydropower project sites. Given the multifaceted, complex nature of demonstrated (Kosnik, 2010) and hypothesized (FERC, 2001) drivers of environmental mitigation requirements, we were uncertain of their predictability. However, we have demonstrated that a broad-scale, multidisciplinary geographical predictor dataset can effectively predict many environmental mitigation requirements across an environmentally and culturally heterogeneous study area.

We summarized and evaluated the influence of the important (relative influence $\geq 5 \%$ ) explanatory variables at several different levels of aggregation (Table 2, Fig. 3, and Fig. 4). Since nearly all the categories (e.g. biological, facility, etc.) of variables were influential within each Tier 1 category (Fig. 3) 
and every Tier 3 model had at least two variable categories represented in the top 3 influential variables (Table 2), it appears that the multi-faceted nature of the predictor dataset we compiled was a key to our modeling success.

Based on our analysis of the top predictor variables across all of the Tier 3 models (Fig. 4), the most common important predictors include metrics of project location (latitude and longitude), project size (annual flow, reservoir size, dam height, and dam length), stream network position (distance along the stream network to network mouth), and climate (precipitation). Elevation above mean sea level, statewide prevalence of local watershed associations, local population density, license issue year, dam length, and dam mode-of-operation were the predictors with the highest average relative influence (Fig. 4) among the most important predictors. Given that the study area is large, environmentally and culturally heterogeneous, and comprised of many diverse physiographic regions, we anticipated latitude and longitude would be valuable predictors that capture regional trends across the U.S. For example, the inclusion of latitude and longitude in models predicting fish passage are related to the fact that most mitigation for passage occurs in the US northeast and northwest. We expected variables related to project size, facility characteristics, and hydrology to be important, given that larger projects are likely to have a higher impact to the environmental and social landscape than smaller projects. Elevation is a proxy for head and a measure of landscape position, and is a very powerful descriptor of landscape context. Stream network position, such as distance to river mouth, can explain presence of diadromous fish species, network connectivity, and existing hydrologic alteration, all of which can heavily influence decisions on mitigation requirements. It is well known in the U.S. that environmental stakeholder groups can be influential in ordered mitigation, so it was not surprising that anthropogenic variables, such as the prevalence of environmental groups, were important. Previous research (Kosnik, 2010) has shown that regulatory trends can influence hydropower mitigation requirements, and the license issue year proved to be an important variable in several models. 
Examination of partial dependence plots to assess the direction of variable influence (Appendix B) seems to show that, while there appears to be some consistent direction of influence for important predictors, particularly in the fish passage and water quality models, there are as many examples of contrasting direction of influence within the six broad mitigation categories. This underscores the complexity of the interplay of the nature and magnitude of a given mitigation requirement with the environmental, economic, political, cultural, and social conditions that coalesce at a project and also underscores the need for further investigation into the causality of different drivers of mitigation.

While it is impractical to research causality for all specific mitigation requirements given the sheer number of different types, we identified several potential future research areas (Table 3) that warrant further investigation. One approach to prioritizing future research into mitigation requirement causality would be to delve further into the socio-political and environmental concerns of non-governmental organizations and environmental resource agencies regarding hydropower development, and how those concerns are manifest in prescribed mitigation. These stakeholder groups have a powerful voice and are important to engage early and throughout the project development process if hydropower's contribution to the U.S. renewable energy portfolio is going to be optimized (Fu et al., 2014). A high-level review of The Nature Conservancy’s Hydropower by Design strategy (The Nature Conservancy, 2015) and American Rivers Hydropower Reform Coalition platform (Hydropower Reform Coalition, 2016) reveals a common theme of maximizing hydropower sustainability through 1) careful selection of dam location within river networks to optimize both hydropower and conservation objectives, 2) implementing cumulative watershed-scale mitigation strategies, 3) reducing uncertainty and risk associated with project development by directing dam development away from environmentally and socially sensitive areas, and 4) improved outcomes for ecosystem services. Future research into the interplay between socio-political demographics, stream connectivity, ecosystem services, and watershed-scale mitigation approaches and their influence on project siting and ultimate success or failure could serve to catalyze future sustainable 
hydropower development in the $21^{\text {st }}$ century (Crook et al., 2015; Fu et al., 2014; Karjalainen and Jarvikoski, 2010; Yu et al., 2016).

Another future direction of this research space is the inclusion of cost estimates for different mitigations, which could inform a cost-based approach for identifying priority mitigation types for future investigation of causality. Cost data would also provide a useful constraint for model predictions. Hydropower projects included in the mitigation database (Fig. 1) have a maximum number of 25 mitigation requirements (of the 49 that we modeled), while the model predictions to NPDs included as many as 34 mitigation requirements. Incorporating cost data would allow for additional realism to be integrated into the predictions by sequentially predicting mitigation types from most to least costly with a control on cost.

Our results should be interpreted with caution given that several models showed significant spatial autocorrelation. Since one of our goals was spatial prediction beyond the spatial extent of our dataset, we did not implement methods for accounting for spatial autocorrelation because previously developed methods do not allow for prediction beyond the dataset (Dormann et al., 2007; Rickbeil et al., 2014). We recognize that our models did not use an independent validation dataset, but rather a split of our original dataset. Since there is no comparable dataset available, we argue that our data split combined with tenfold internal cross-validation allowed for reliable evaluation of model performance to be made (Rickbeil et al., 2014).

The BRT models could potentially be improved by improving some of the more coarse resolution predictors - such as those derived at the state-scale - to represent a more refined local scale. A disconnect may exist between the spatial scale at which mitigation requirements are ordered and the scale at which some of our explanatory variables are derived. This disparity of scales and varying resolution of predictors can affect the apparent importance of a predictor variable (Brewer et al., 2007). Schramm et al. (2016)described several possible limitations to the development of the mitigation database, which was limited to a review of mitigation prescribed explicitly in FERC licenses issued from 1998 to 2015. More 
specifically, some of the reviewed licenses were for relicensing of existing projects and thus may not include previously required mitigation under the original license. Also, FERC encourages the use of settlement agreements (legal agreements developed between hydropower developers, agencies, and other stakeholders on project operations and environmental conditions) that may include mitigation not included in the final license.

\section{CONCLUSION}

We demonstrated in this study an approach including specific statistical models that can be used by developers and regulators alike to identify and anticipate likely environmental mitigation at existing and proposed hydropower projects in the U.S. The results demonstrate that mitigation requirements in existing licenses have been a result of a range of factors from biological and hydrological to political and cultural. That such a range of variable types is needed to predict mitigation requirements explains much of the difficulty and uncertainty that surrounds the development of effective environmental mitigation during the licensing process in the U.S. Further research is needed to establish robust links between specific explanatory variables, mitigation requirements, and mitigation strategies. However, use of these models by developers can reduce uncertainty with regards to cost projections and inform decisions about project design. Regulators will be able to use the models to more quickly identify likely environmental issues and potential solutions, hopefully resulting in more timely and more effective decisions on environmental mitigation.

\section{ACKNOWLEDGEMENTS}

We would like to thank R. McManamay for statistical advice, suggestions for predictor variables, and valuable comments on this manuscript. We also thank S.C. Kao for assistance with the NHAAP database and FERC licenses. This study was funded by the U.S. Department of Energy (DOE) Energy Efficiency and Renewable Energy Office, Wind and Water Power Technologies Program through Oak Ridge 
National Laboratory, which is managed by UT-Battelle, LLC, for the DOE under contract DE-AC05-

00OR22725.

\section{REFERENCES}

Abram NK, Meijaard E, Wells JA, Ancrenaz M, Pellier A-S, Runting RK, et al. Mapping perceptions of species' threats and population trends to inform conservation efforts: the Bornean orangutan case study. Diversity and Distributions 2015; 21: 487-499.

Araujo M, Guisan A. Five (or so) challenges for species distribution modelling. Journal of Biogeography 2006; 33: 1677-1688.

Arganaraz J, Pizarro G, Zak M, Landi M, Bellis L. Human and biophysical drivers of fires in Semiarid Chaco mountains of Central Argentina. Science of the Total Environment 2015; 520: 1-12.

Blumm MC, Nadol VA. The decline of the hydropower czar and the rise of agency pluralism in hydroelectric licensing. Columbia Journal of Environmental Law 2001; 26.

Brewer SK, Rabeni CF, Sowa SP, Annis G. Natural landscape and stream segment attributes influencing the distribution and relative abundance of riverine smallmouth bass in Missouri. North American Journal of Fisheries Management 2007; 27: 326-341.

Bunn S, Arthington A. Basic principles and ecological consequences of altered flow regimes for aquatic biodiversity. Environmental Management 2002; 30: 492-507.

Cada GF. Fish passage mitigation at hydroelectric power projects in the United States. Fish Migration and Fish Bypasses 1998: 208-219.

Crook D, Lowe W, Allendorf F, Eros T, Finn D, Gillanders B, et al. Human effects on ecological connectivity in aquatic ecosystems: Integrating scientific approaches to support management and mitigation. Science of the Total Environment 2015; 534: 52-64.

Deshazo JR, Freeman J. Public Agencies as Lobbyists. Columbia Law Review 2005; 105.

Dormann C, Elith J, Bacher S, Buchmann C, Carl G, Carre G, et al. Collinearity: a review of methods to deal with it and a simulation study evaluating their performance. Ecography 2013; 36: 27-46.

Dormann C, McPherson J, Araujo M, Bivand R, Bolliger J, Carl G, et al. Methods to account for spatial autocorrelation in the analysis of species distributional data: a review. Ecography 2007; 30: 609628.

Elith J, Graham C, Anderson R, Dudik M, Ferrier S, Guisan A, et al. Novel methods improve prediction of species' distributions from occurrence data. Ecography 2006; 29: 129-151.

Elith J, Leathwick J, Hastie T. A working guide to boosted regression trees. Journal of Animal Ecology 2008; 77: 802-813. 
FERC. Report on hydroelectric licensing policies, procedures, and regulations, http://www.ferc.gov/legal/maj-ord-reg/land-docs/ortc_final.pdf (accessed 1.15.15), 2001.

FERC. workload, http://www.ferc.gov/industries/hydropower/gen-info/licensing/workload.xls (accessed 1.15.15), 2015.

Fink D, Hochachka W, Zuckerberg B, Winkler D, Shaby B, Munson M, et al. Spatiotemporal exploratory models for broad-scale survey data. Ecological Applications 2010; 20: 2131-2147.

Fraley J, Marotz B, Decker-Hess J, Beattie W, Zubik R. Mitigation, compensation, and future protection for fish populations affected by hydropower development in the upper Columbia system, Montana, U.S.A. River Research and Applications 1989; 3: 3-18.

Fu B, Wang Y, Xu P, Yan K, Li M. Value of ecosystem hydropower service and its impact on the payment for ecosystem services. Science of the Total Environment 2014; 472: 338-346.

Grimm N, Foster D, Groffman P, Grove J, Hopkinson C, Nadelhoffer K, et al. The changing landscape: ecosystem responses to urbanization and pollution across climatic and societal gradients. Frontiers in Ecology and the Environment 2008; 6: 264-272.

Guisan A, Thuiller W. Predicting species distribution: offering more than simple habitat models. Ecology Letters 2005; 8: 993-1009.

Hadjerioua B, Wei Y, Kao S-C. An Assessment of Energy Potential at Non-Powered Dams in the United States. ORNL/TM-2011/341. Oak Ridge National Laboratory, 2012.

Hosmer DW, Lemeshow S, Sturdivant RX. Applied Logistic Regression. Hoboken, NJ, U.S.A.: John Wiley \& Sons, 2013.

Hydropower Reform Coalition. Platform, http://hydroreform.org/sites/default/files/HRC\%20Platform_2.pdf (accessed 2.15.16), 2016.

Karjalainen TP, Jarvikoski TB. Negotiating river ecosystems: Impact assessment and conflict mediation in the cases of hydro-power construction. Environmental Impact Assessment Review 2010; 30: 319-327.

Knittel CR. The Adoption of State Electricity Regulation: The Role of Interest Groups. Journal of Industrial Economics 2006; 54: 201-222.

Kosnik L. Balancing Environmental Protection and Energy Production in the Federal Hydropower Licensing Process Land Economics 2010; 86: 444-466.

Kuby MJ, Fagan WF, ReVelle CS, Graf WL. A multiobjective optimization model for dam removal: an example trading off salmon passage with hydropower and water storage in the Willamette basin. Advances in Water Resources 2005; 28: 845-855.

Kuhn M. Building Predictive Models in R Using the caret Package. Journal of Statistical Software 2008; 28: 1-26.

Liermann C, Nilsson C, Robertson J, Ng R. Implications of Dam Obstruction for Global Freshwater Fish Diversity. Bioscience 2012; 62: 539-548. 
Ligon FK, Dietrich WE, Trush WJ. Downstream ecological effects of dams. Bioscience 1995; 45: 183192.

Manzano-Agugliaro F, Alcayde A, Montoya F, Zapata-Sierra A, Gil C. Scientific production of renewable energies worldwide: An overview. Renewable \& Sustainable Energy Reviews 2013; 18: 134-143.

McManamay R, Samu N, Kao S, Bevelhimer M, Hetrick S. A Multi-scale Spatial Approach to Address Environmental Effects of Small Hydropower Development. Environmental Management 2015; 55: 217-243.

Moore ID, Grayson RB, Ladson AR. Digital Terrain Modeling - A review of hydrological, geomorphological, and biological applications. Hydrological Processes 1991; 5: 3-30.

NatureServe. Digital Distribution Maps of the Freshwater Fishes in the Conterminous United States, Arlington, VA. U.S.A., 2010.

Nilsson C, Reidy C, Dynesius M, Revenga C. Fragmentation and flow regulation of the world's large river systems. Science 2005; 308: 405-408.

Oppel S, Meirinho A, Ramirez I, Gardner B, O'Connell A, Miller P, et al. Comparison of five modelling techniques to predict the spatial distribution and abundance of seabirds. Biological Conservation 2012; 156: 94-104.

Parisien M, Parks S, Krawchuk M, Flannigan M, Bowman L, Moritz M. Scale-dependent controls on the area burned in the boreal forest of Canada, 1980-2005. Ecological Applications 2011; 21: 789805.

Peltzman S. Toward a more general theory of regulation. Journal of Law and Economics 1976; 19: 211240.

Poff N, Allan J, Bain M, Karr J, Prestegaard K, Richter B, et al. The natural flow regime. Bioscience 1997; 47: 769-784.

Poff N, Olden J, Merritt D, Pepin D. Homogenization of regional river dynamics by dams and global biodiversity implications. Proceedings of the National Academy of Sciences of the United States of America 2007; 104: 5732-5737.

R-Core-Team. R: a language and environment for statistical computing, Vienna, Austria. Version 3.2.2. Available at https://www.r-project.org/. R Foundation for Statistical Computing, 2015.

Renofalt B, Jansson R, Nilsson C. Effects of hydropower generation and opportunities for environmental flow management in Swedish riverine ecosystems. Freshwater Biology 2010; 55: 49-67.

Rickbeil G, Coops N, Drever M, Nelson T. Assessing coastal species distribution models through the integration of terrestrial, oceanic and atmospheric data. Journal of Biogeography 2014; 41: 16141625.

Schramm MP, Bevelhimer MS, DeRolph CR. A synthesis of environmental and recreational mitigation requirements at hydropower projects in the United States. Environmental Science \& Policy 2016; 61: 87-96. 
Shmueli G. To Explain or to Predict? Statistical Science 2010; 25: 289-310.

Tarlock D. Hydro law and the future of hydroelectric power generation in the United States. Vanderbilt Law Review 2012; 65: 1723-1767.

The Nature Conservancy. The Power of Rivers, http://www.nature.org/media/freshwater/power-of-riversreport.pdf (accessed 2.15.16), 2015.

Tong S, Chen W. Modeling the relationship between land use and surface water quality. Journal of Environmental Management 2002; 66: 377-393.

Trussart S, Messier D, Roquet V, Aki S. Hydropower projects: a review of most effective mitigation measures. Energy Policy 2002; 30: 1251-1259.

U.S.-Congress. House Commitee on Natural Resources. Mandatory conditioning requirements on hydropower: How federal resources agencies are driving up electricity costs and decreasing the original green energy, 2012.

VanDerWal J, Falconi L, Januchowski S, Shoo L, Storlie C. Package 'SDMTools', http://cran.rproject.org/web/packages/SDMTools/index.html (accessed August 2015), 2012.

Wang L, Lyons J, Kanehl P. Impacts of urbanization on stream habitat and fish across multiple spatial scales. Environmental Management 2001; 28: 255-266.

Yu B, Xu L. Review of ecological compensation in hydropower development. Renewable \& Sustainable Energy Reviews 2016; 55: 729-738.

Yu B, Xu L, Yang Z. Ecological compensation for inundated habitats in hydropower developments based on carbon stock balance Journal of Cleaner Production 2016; 114: 334-342. 
Appendix A

Mitigation categories in the hierarchical database and the percent of times each was required. Bold indicates model was fit for mitigation category.

\begin{tabular}{|c|c|c|c|c|}
\hline Tier 1 & Tier 2 & Tier 3 & ModelID & Percent required \\
\hline \multirow[t]{48}{*}{ Fish Passage } & -- & -- & $\mathrm{F} 1$ & $48.8 \%$ \\
\hline & \multirow[t]{15}{*}{ Downstream Fish Passage } & -- & F101 & $24.9 \%$ \\
\hline & & Surface Collector & F101001 & $1.9 \%$ \\
\hline & & Trap and Transport & F101002 & $1.4 \%$ \\
\hline & & Modification of Spill or Gate Operation & F 101003 & $3.3 \%$ \\
\hline & & Sluiceway & F101004 & $0.4 \%$ \\
\hline & & Bypass Facility & F 101005 & $2.1 \%$ \\
\hline & & Conduit & F101006 & $1.2 \%$ \\
\hline & & Fish Friendly Turbine & F 101007 & $0.2 \%$ \\
\hline & & Generation Shut Down & F101008 & $2.1 \%$ \\
\hline & & Flashboard Removal or Modification & F 101009 & $0.2 \%$ \\
\hline & & Downstream Passage Plan Study Design & F101010 & $15.5 \%$ \\
\hline & & Modify spill or gate design & F101011 & $2.7 \%$ \\
\hline & & Modify sluiceway & F101012 & $1.6 \%$ \\
\hline & & Modify bypass facility & F 101013 & $0.2 \%$ \\
\hline & & Modify intake & F 101014 & $0.2 \%$ \\
\hline & \multirow[t]{14}{*}{ Upstream Fish Passage } & -- & F102 & $19.4 \%$ \\
\hline & & Adult fishway & F102015 & $0.4 \%$ \\
\hline & & Conduit & F 102016 & $0.2 \%$ \\
\hline & & Eclway & F102017 & $7.4 \%$ \\
\hline & & Fish Ladder & F102018 & $3.3 \%$ \\
\hline & & Lock or elcvator & F102019 & $2.3 \%$ \\
\hline & & Modify spill or gate opcration & F 102020 & $0.2 \%$ \\
\hline & & Tailrace exclusion device & F102021 & $2.5 \%$ \\
\hline & & Trap and transport & F102022 & $4.3 \%$ \\
\hline & & Upstream passage study plan or design & F102023 & $12.2 \%$ \\
\hline & & Modify adult fishway & F 102024 & $0.2 \%$ \\
\hline & & Modify fish ladder & F 102025 & $0.8 \%$ \\
\hline & & Modify lock or lift & F102026 & $0.2 \%$ \\
\hline & & Modify trap and transport & F 102027 & $0.6 \%$ \\
\hline & \multirow[t]{10}{*}{ Passage Planning } & - & F103 & $26.2 \%$ \\
\hline & & Design plan entrainment avoidance system & F 103028 & $1.6 \%$ \\
\hline & & Downstream fish passage monitoring sampling & F103029 & $13.6 \%$ \\
\hline & & Entrainment or turbine mortality monitoring & F 103030 & $3.7 \%$ \\
\hline & & Fish passage and operations plan & F103031 & $7.4 \%$ \\
\hline & & Fish passage feasibility assessment & F103032 & $3.1 \%$ \\
\hline & & Fish stranding plan monitoring evaluation & F103033 & $7.2 \%$ \\
\hline & & Fisheries disease management & F 103034 & $0.6 \%$ \\
\hline & & Hatchery operations and management & F103035 & $1.9 \%$ \\
\hline & & Upstream fish passage monitoring sampling & F103036 & $10.7 \%$ \\
\hline & \multirow[t]{8}{*}{ Fntrainment } & -- & F104 & $23.9 \%$ \\
\hline & & Barrier or guidance net & F 104037 & $1.6 \%$ \\
\hline & & Fish screen & F104038 & $4.3 \%$ \\
\hline & & Gatewell exclusion screen & F104039 & $0.4 \%$ \\
\hline & & Perforated plate & F 104040 & $0.2 \%$ \\
\hline & & Solid panel and bar rack & F104041 & $0.4 \%$ \\
\hline & & Strobe light & F104042 & $0.2 \%$ \\
\hline & & Trash or bar rack & F104043 & $17.1 \%$ \\
\hline \multirow[t]{12}{*}{ Hydrology } & -- & -- & $\mathrm{F} 2$ & $95.1 \%$ \\
\hline & \multirow{11}{*}{ Flow Mitigation } & -- & F205 & $61.9 \%$ \\
\hline & & Tailrace adaptive flow management & F205044 & $1.6 \%$ \\
\hline & & Tailrace flow monitoring plan & F205045 & $34.0 \%$ \\
\hline & & Tailrace flow studies & F205046 & $3.5 \%$ \\
\hline & & Tailrace flushing or flood flows & F205047 & $1.9 \%$ \\
\hline & & Tailrace flow or stage monitoring equipment & F205048 & $14.2 \%$ \\
\hline & & Tailrace flow control device & F205049 & $2.7 \%$ \\
\hline & & Tailrace ramping rate restriction & F205050 & $11.1 \%$ \\
\hline & & Bypass adaptive flow management & F205051 & $1.9 \%$ \\
\hline & & Bypass flow monitoring plan & F205052 & $12.8 \%$ \\
\hline & & Bypass flow study & F205053 & $2.5 \%$ \\
\hline
\end{tabular}


Appendix A

Mitigation categories in the hicrarchical database and the percent of times each was required. Bold indicates model was fit for mitigation category.

\begin{tabular}{|c|c|c|c|c|}
\hline Tier 1 & Tier 2 & Tier 3 & ModelID & Percent required \\
\hline & & Bypass flushing or flood flow & F205054 & $5.6 \%$ \\
\hline & & Bypass flow or stage monitoring equipment & F205055 & $7.2 \%$ \\
\hline & & Bypass flow control device & F205056 & $0.8 \%$ \\
\hline & & Bypass ramping rate restriction & F205057 & $6.2 \%$ \\
\hline & \multirow[t]{5}{*}{ Tailrace Minimum Flow } & -- & F206 & $64.5 \%$ \\
\hline & & Run-of-river Tailrace & F206058 & $39.0 \%$ \\
\hline & & Seasonal Tailrace & F206059 & $13.6 \%$ \\
\hline & & Seasonal and type of year Tailrace & F206060 & $1.6 \%$ \\
\hline & & Year-round Tailrace & F206061 & $10.3 \%$ \\
\hline & \multirow{4}{*}{ Bypass Minimum Flow } & -- & F207 & $41.9 \%$ \\
\hline & & Seasonal Bypass & F207063 & $17.1 \%$ \\
\hline & & Seasonal and type of year Bypass & F207064 & $4.5 \%$ \\
\hline & & Year-round Bypass & F207065 & $20.2 \%$ \\
\hline & \multirow[t]{5}{*}{ Sediment } & -- & F208 & $42.9 \%$ \\
\hline & & Sediment and erosion control plan or monitoring & F208066 & $41.6 \%$ \\
\hline & & Dredging & F208067 & $0.2 \%$ \\
\hline & & Install or operate gate to flush sediment & F208068 & $0.8 \%$ \\
\hline & & Sediment flushing flows & F208069 & $0.8 \%$ \\
\hline & \multirow[t]{4}{*}{ Recreation Flow } & -- & F209 & $13.2 \%$ \\
\hline & & Maintain recreational lake levels & F 209070 & $3.3 \%$ \\
\hline & & Provide recreational flow releases or structures & F209071 & $9.7 \%$ \\
\hline & & Recreational flow studies & F209072 & $4.1 \%$ \\
\hline & \multirow[t]{4}{*}{ Operations } & -- & F210 & $54.8 \%$ \\
\hline & & Flow management plan & F210073 & $6.6 \%$ \\
\hline & & Operations compliance monitoring plan & F210074 & $40.6 \%$ \\
\hline & & Provide flow or lake levels electronically & F210075 & $10.7 \%$ \\
\hline \multirow{19}{*}{ Water Quality } & -- & -- & F3 & $53.7 \%$ \\
\hline & \multirow[t]{12}{*}{ Downstream Water Quality } & -- & F311 & $54.0 \%$ \\
\hline & & $\Lambda$ daptive water quality management & F311076 & $3.7 \%$ \\
\hline & & Benthic macroinvertebrate monitoring & F311077 & $5.4 \%$ \\
\hline & & DO enhancement or mitigation plan & F311078 & $5.4 \%$ \\
\hline & & Establish or fund water quality stations and stream gages & F311079 & $3.3 \%$ \\
\hline & & Forebay aeration & F311080 & $0.2 \%$ \\
\hline & & Operational changes & F311081 & $2.7 \%$ \\
\hline & & Powerhouse aeration & F311082 & $2.1 \%$ \\
\hline & & Tailrace structures for aeration & F311083 & $0.2 \%$ \\
\hline & & Temperature regulating device or structure & F311084 & $0.6 \%$ \\
\hline & & Temperature regulation or mitigation plan & F 311085 & $0.4 \%$ \\
\hline & & Water quality monitoring plan & F311086 & $50.3 \%$ \\
\hline & \multirow[t]{6}{*}{ Upstream Water Quality } & -- & F312 & $24.5 \%$ \\
\hline & & Fish tissuc sampling and analysis & F312087 & $8.2 \%$ \\
\hline & & Impoundment sediment analysis & F312088 & $6.4 \%$ \\
\hline & & Macroinvertebrate monitoring & F312089 & $0.6 \%$ \\
\hline & & Inflow water quality monitoring plan & F312090 & $8.9 \%$ \\
\hline & & Impoundment water quaity monitoring plan & F312091 & $17.3 \%$ \\
\hline \multirow[t]{15}{*}{ Biodiversity } & -- & -- & F4 & $71.4 \%$ \\
\hline & \multirow[t]{8}{*}{ Terrestrial } & -- & F413 & $66.6 \%$ \\
\hline & & Acquistion easements conservation or important habitat & F413092 & $4.1 \%$ \\
\hline & & Install upgrade monitor wildlife crossings & F413093 & $4.1 \%$ \\
\hline & & Noxious terrestrial weed and invasive plant management & F413094 & $25.6 \%$ \\
\hline & & Species conservation management monitoring & F413095 & $42.9 \%$ \\
\hline & & Threatened and endangered species protection plan & F413096 & $10.9 \%$ \\
\hline & & Transmission related avaian and bat protection & $\mathbf{F 4 1 3 0 9 7}$ & $15.5 \%$ \\
\hline & & Wildlife terrestrial habitat management & F413098 & $27.0 \%$ \\
\hline & \multirow[t]{6}{*}{ Aquatic } & -- & F414 & $35.5 \%$ \\
\hline & & Adaptive fishery management & F414099 & $3.9 \%$ \\
\hline & & Aquatic species conservation management monitoring & F414100 & $25.6 \%$ \\
\hline & & Diadromous species management monitoring & F414101 & $7.4 \%$ \\
\hline & & Invasive aquatic species management (fish and molluscs) & F414102 & $9.3 \%$ \\
\hline & & Stocking fish species of concern & Г414103 & $4.5 \%$ \\
\hline
\end{tabular}


Appendix A

Mitigation categories in the hierarchical database and the percent of times each was required. Bold indicates model was fit for mitigation category.

\begin{tabular}{|c|c|c|c|c|}
\hline Tier 1 & Tier 2 & Tier 3 & ModelID & Percent required \\
\hline \multirow[t]{19}{*}{ Habitat } & -- & -- & F5 & $57.1 \%$ \\
\hline & \multirow[t]{5}{*}{ Fisheries } & -- & F515 & $26.8 \%$ \\
\hline & & Downstream gravel and sediment restoration & F515104 & $4.5 \%$ \\
\hline & & Downstream habitat enhancement & F515105 & $8.7 \%$ \\
\hline & & Downstream woody debris restoration or passage & F515106 & $15.9 \%$ \\
\hline & & Reservoir fishery habitat enhancement & F515133 & $3.3 \%$ \\
\hline & \multirow{5}{*}{ Riparian } & -- & F516 & $20.4 \%$ \\
\hline & & Dust control and abatement & F516107 & $0.6 \%$ \\
\hline & & Establish riparian buffers & F516108 & $7.2 \%$ \\
\hline & & Riparian habitat enhancement & F516109 & $4.7 \%$ \\
\hline & & Riparian habitat monitoring or planning & F516110 & $12.0 \%$ \\
\hline & \multirow[t]{3}{*}{ Reservoir } & -- & F517 & $31.8 \%$ \\
\hline & & Noxious invasive aquatic plant management & F517111 & $21.0 \%$ \\
\hline & & Shoreline management plan or program & F517112 & $16.1 \%$ \\
\hline & \multirow[t]{5}{*}{ Wetlands } & - & F518 & $11.5 \%$ \\
\hline & & Wetland enhancement & F518113 & $0.8 \%$ \\
\hline & & Wetland mitigation & F518114 & $4.9 \%$ \\
\hline & & Wetland monitoring & F518115 & $2.9 \%$ \\
\hline & & Wetland protection & F518116 & $6.8 \%$ \\
\hline \multirow[t]{19}{*}{ Recreation } & -- & -- & F6 & $82.3 \%$ \\
\hline & \multirow[t]{16}{*}{ Resources and Mitigation } & -- & F619 & $66.2 \%$ \\
\hline & & Appoint historic cultural resource coordinator & F619117 & $0.4 \%$ \\
\hline & & Boating facilities & F619118 & $23.1 \%$ \\
\hline & & Canoe portage launch & F619119 & $24.1 \%$ \\
\hline & & Fishing pier & F619120 & $8.9 \%$ \\
\hline & & Floating debris removal & F619121 & $1.0 \%$ \\
\hline & & Install fish attracting structure for recreational fishing & F619122 & $2.7 \%$ \\
\hline & & Interpretive education sign and displays & F619123 & $15.5 \%$ \\
\hline & & Navigational aids and improvements & F619124 & $1.0 \%$ \\
\hline & & Parking & F619125 & $26.4 \%$ \\
\hline & & Protection of specific historic cultural resource sites & F619126 & $3.3 \%$ \\
\hline & & Public outreach education programs & F 619127 & $0.6 \%$ \\
\hline & & Shoreline access & F619128 & $17.9 \%$ \\
\hline & & Stocking recreational fish species & F619129 & $6.6 \%$ \\
\hline & & Trail trailhead or camping areas & F619130 & $14.2 \%$ \\
\hline & & Other day use area improvements & F619132 & $35.3 \%$ \\
\hline & \multirow[t]{2}{*}{ Planning } & -- & F620 & $72.8 \%$ \\
\hline & & Recreational management plan study or monitoring & F620131 & $72.8 \%$ \\
\hline
\end{tabular}




\section{Appendix B}

Partial dependence plots for the three variables with the highest relative influence for each Tier 2 and Tier 3 model with an internal CV ROC and independent $\mathrm{ROC} \geq 0.7$

NOTES: The ModelID for each model is shown in the upper-right hand corner of each set of three partial dependence plots; see Table 1 for variable descriptions; see Table 2 for details on mitigation types; ticks across the top of each plot show the distribution of deciles for each predictor variable.

\section{Definitions for categorical variables}

\begin{tabular}{ll}
\hline Mode & Value \\
\hline Canal/Conduit & $\mathrm{C}$ \\
Intermediate Peaking & $\mathrm{I}$ \\
Peaking & $\mathrm{P}$ \\
Pumped Storage & $\mathrm{S}$ \\
Reregulating & $\mathrm{R}$ \\
Run-of-river & $\mathrm{O}$ \\
Run-of-river/Peaking & $\mathrm{A}$ \\
Run-of-river/Upstream Peaking & $\mathrm{B}$ \\
& \\
& \\
\hline owner & Value \\
\hline Cooperative & $\mathrm{C}$ \\
Private & $\mathrm{P}$ \\
Public & $\mathrm{U}$ \\
Wholesale Power Marketer & $\mathrm{W}$ \\
& \\
\hline PrmryPurps & $\mathrm{I}$ \\
\hline Flood control and stormwater & Value \\
management & $\mathrm{C}$ \\
Fish and wildlife pond & $\mathrm{F}$ \\
Hydroelectric & $\mathrm{H}$ \\
Navigation & $\mathrm{N}$ \\
Other & $\mathrm{O}$ \\
Recreation & \\
Water supply & \\
\hline
\end{tabular}


Tier 2 Fish Passage
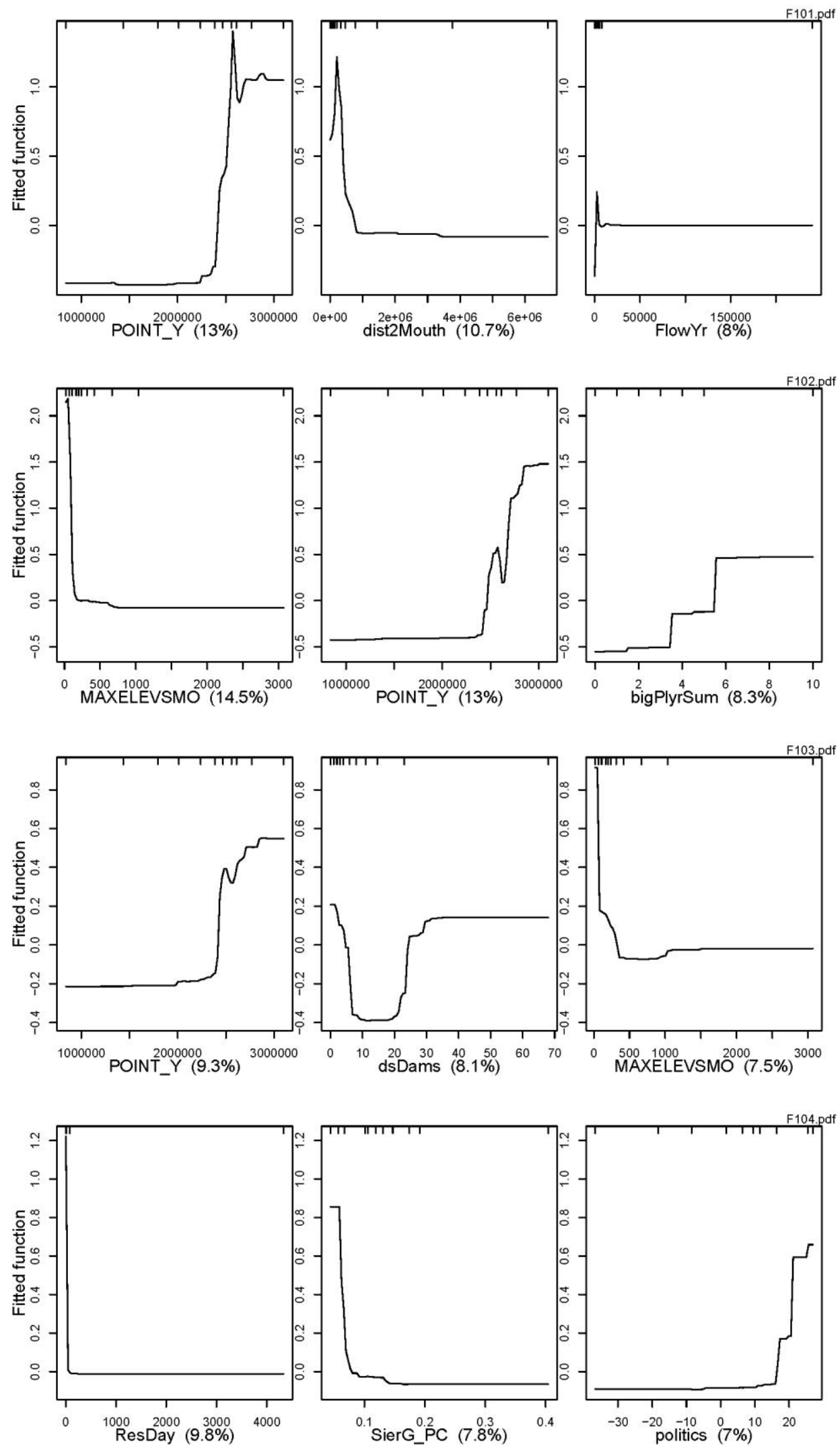
Tier 3 Fish Passage
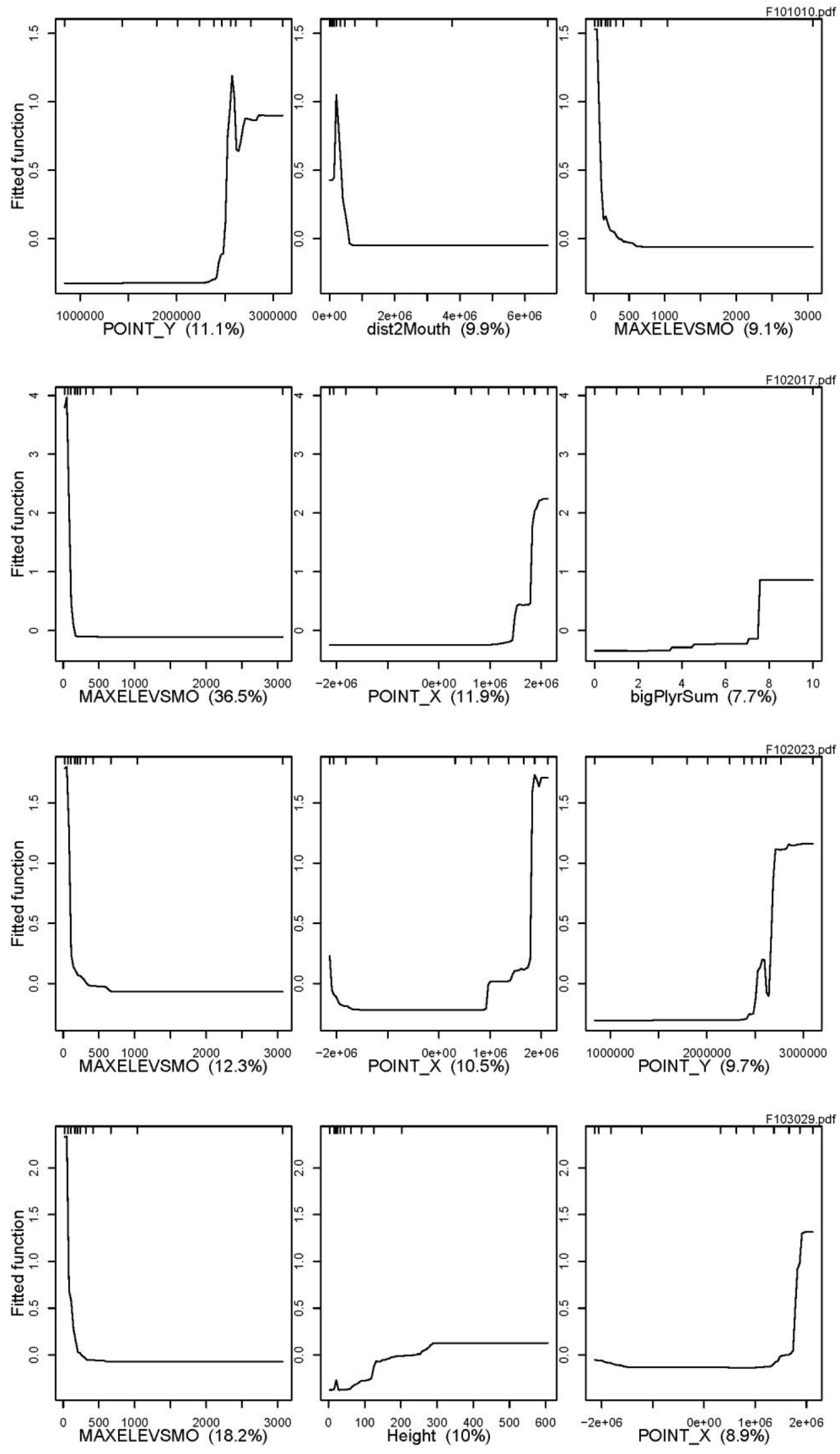

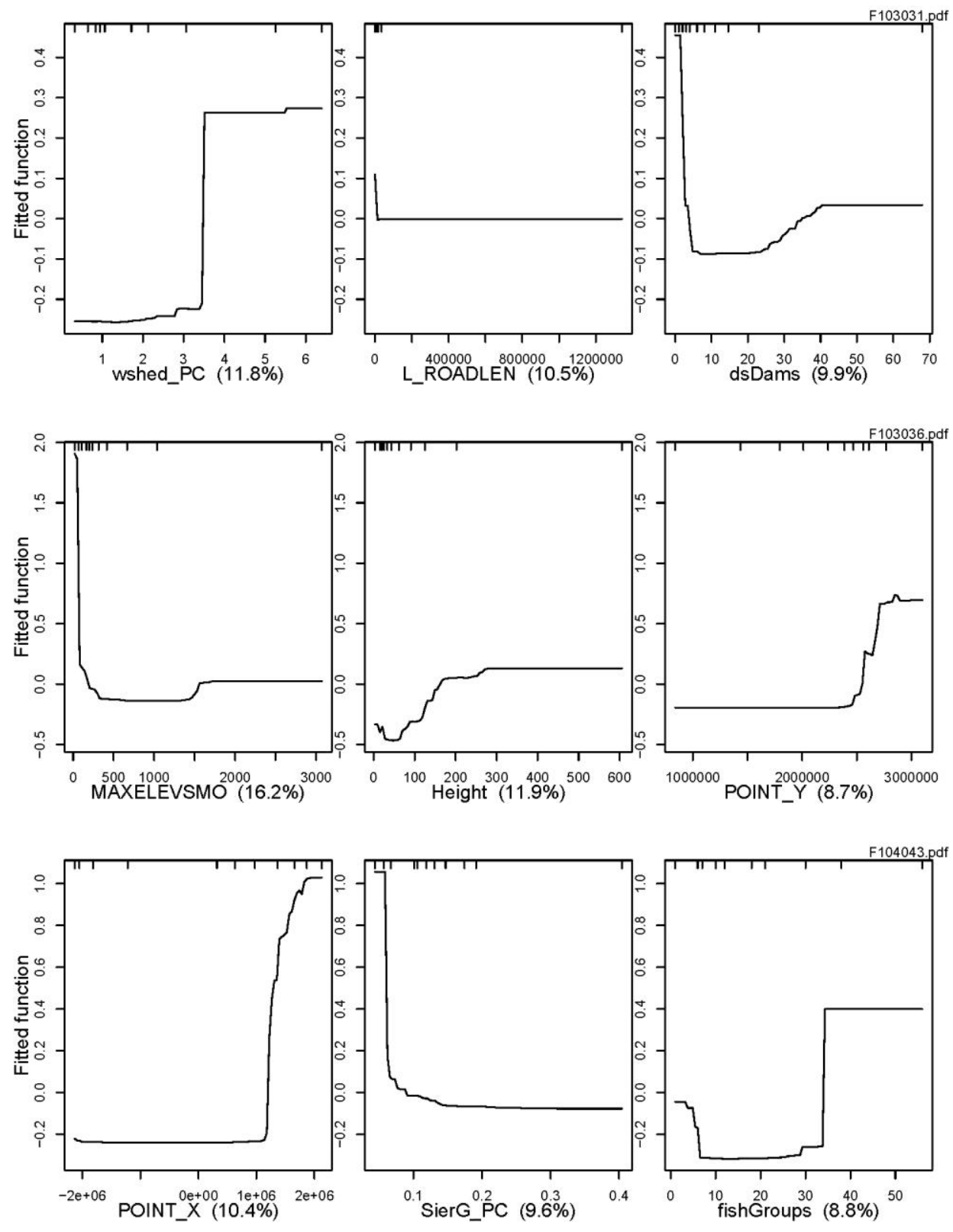

\section{Tier 2 Hydrology}
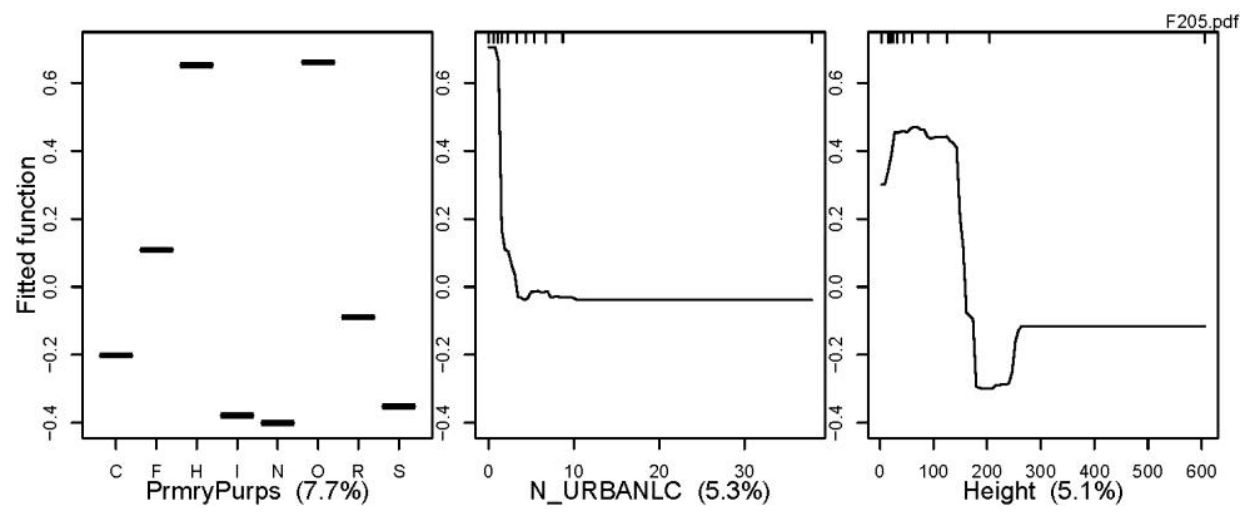

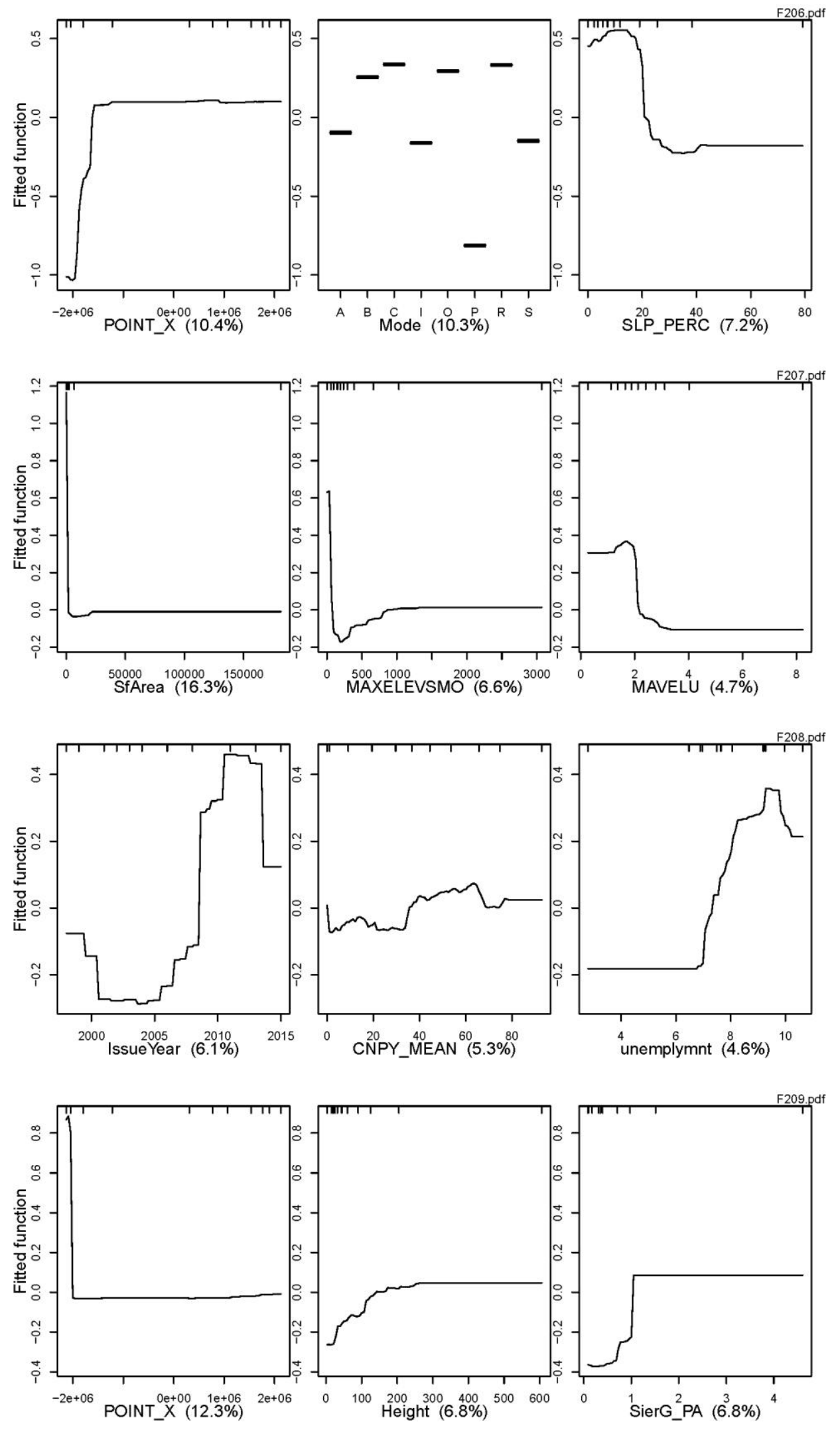

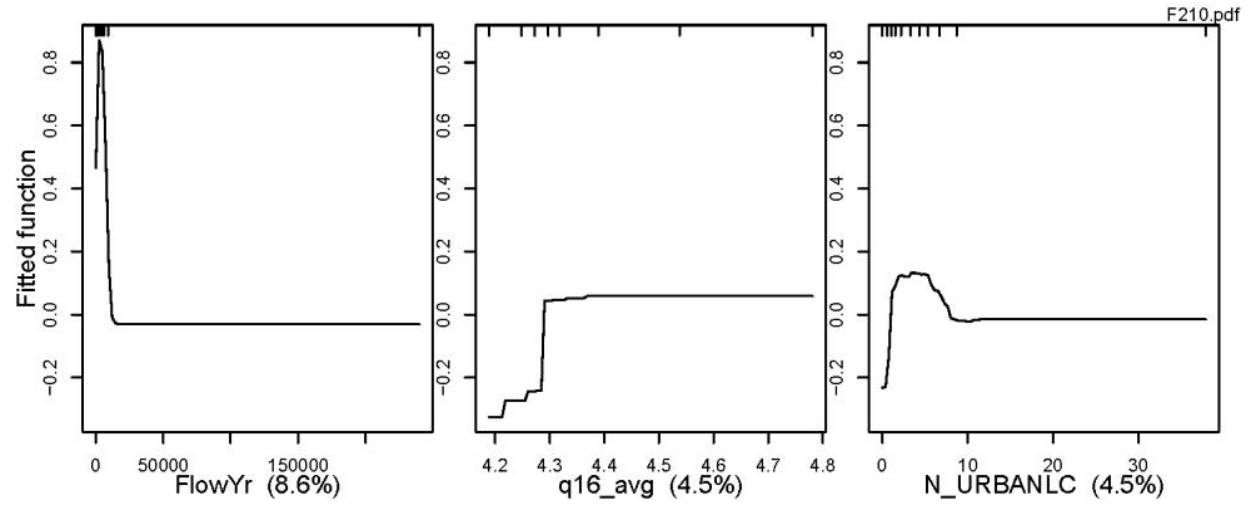

\section{Tier 3 Hydrology}
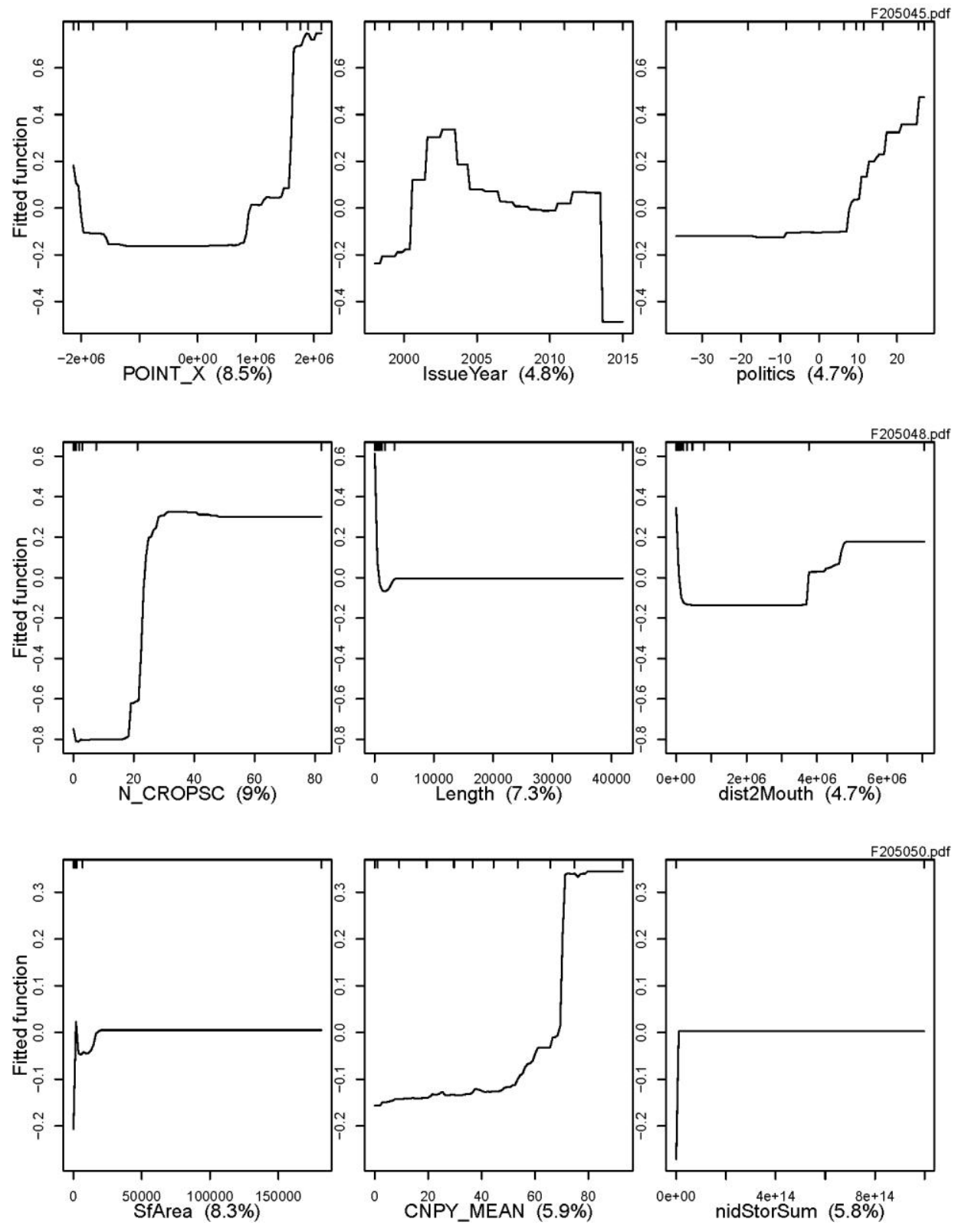

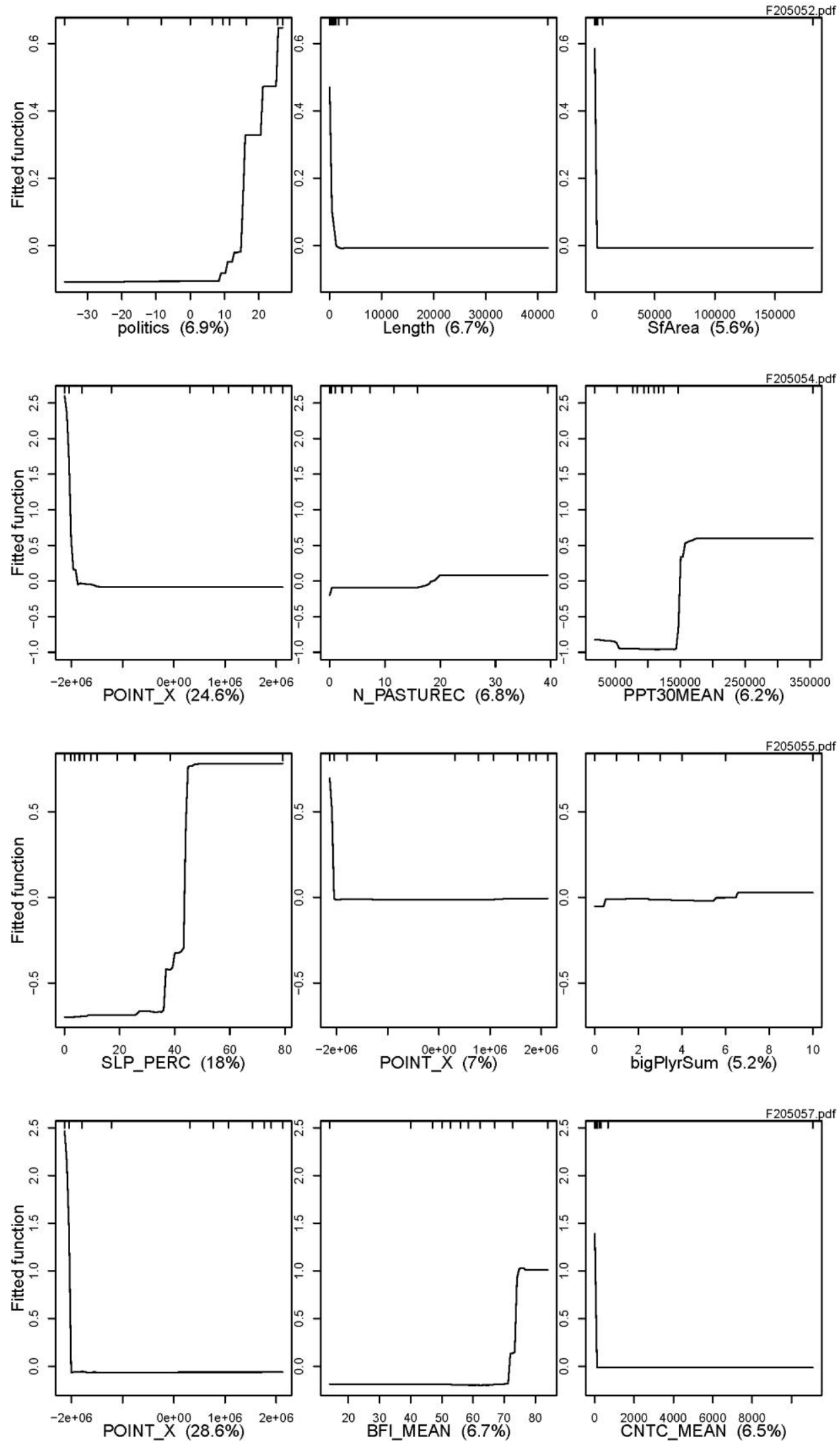

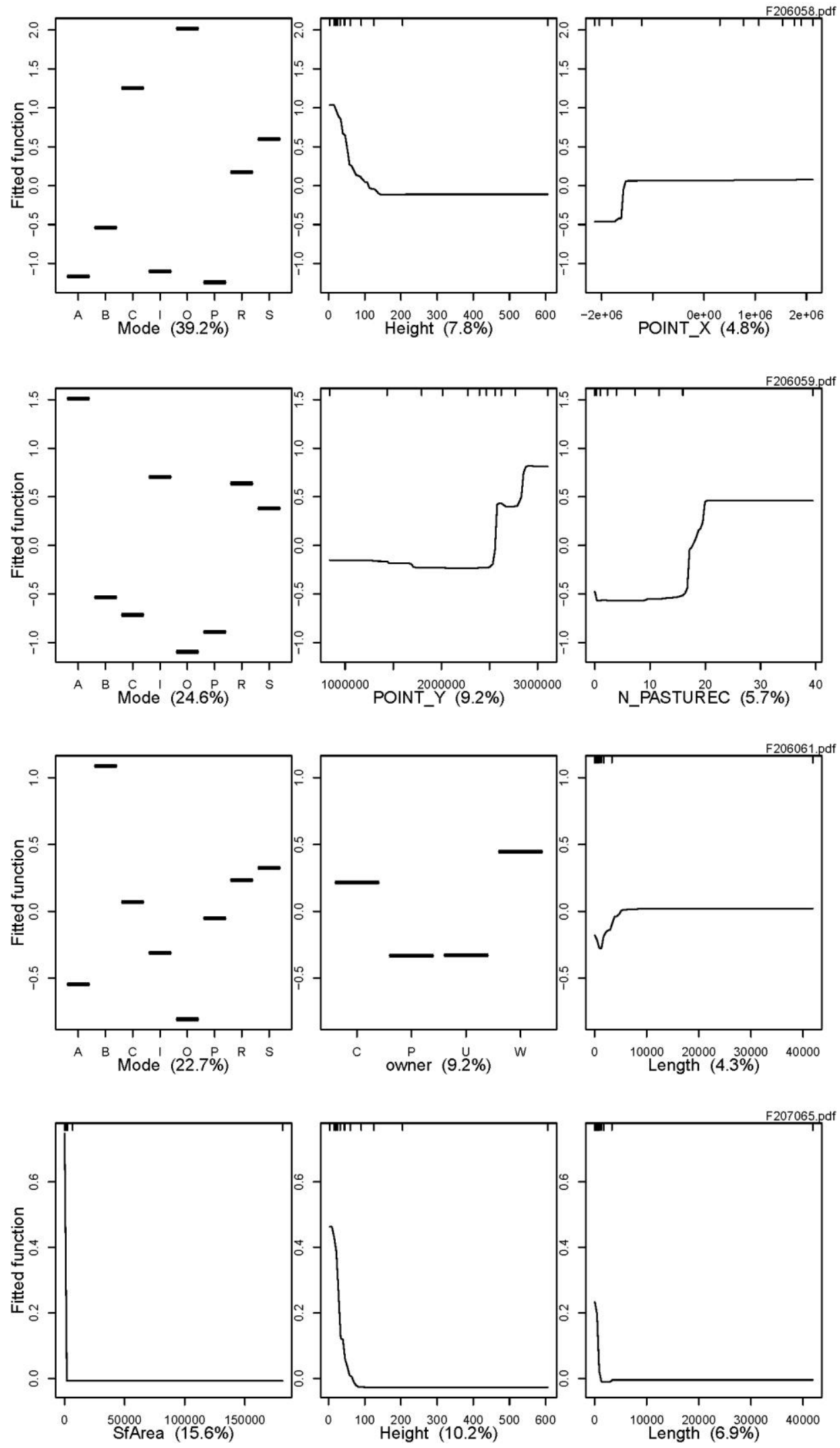

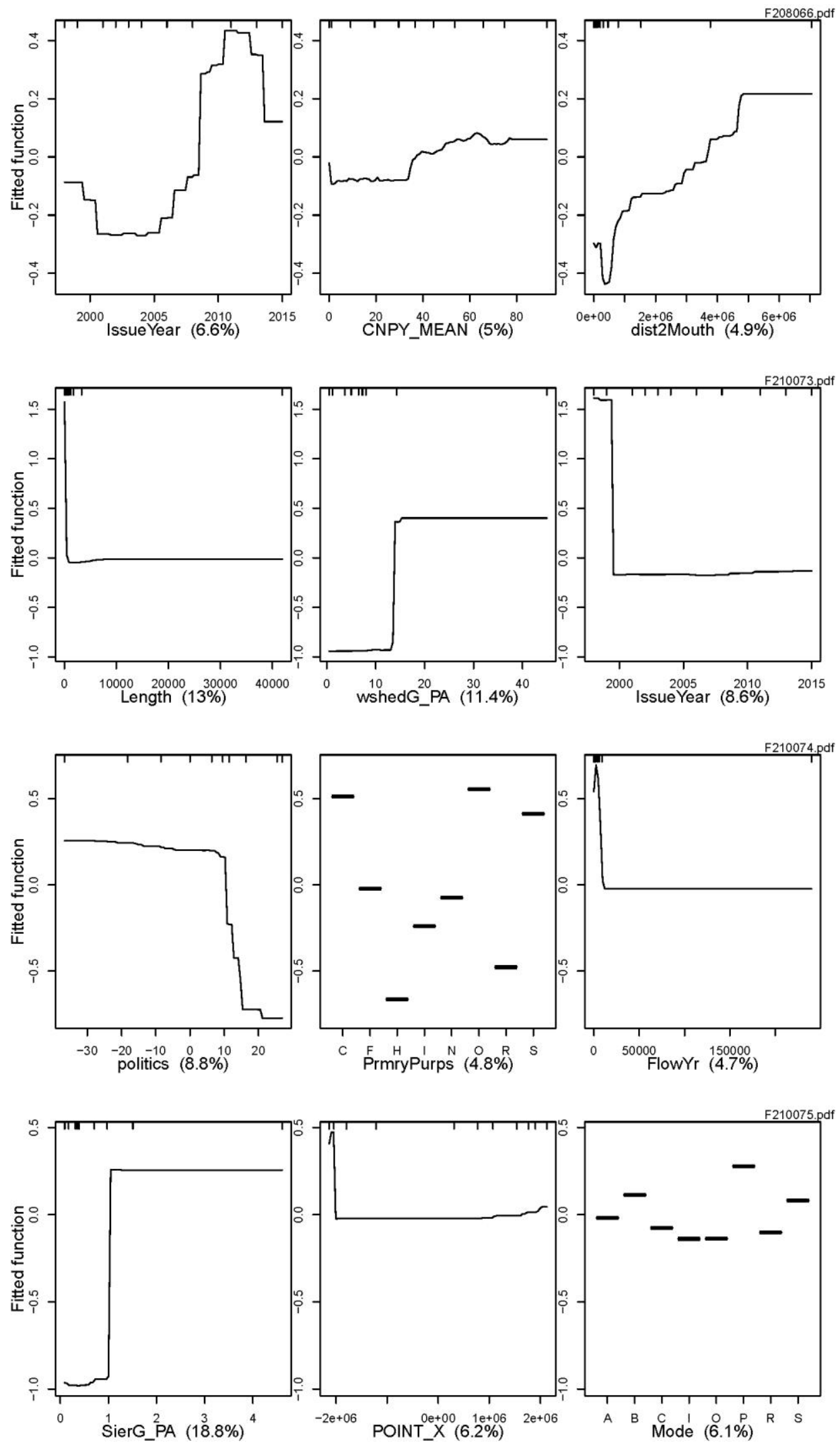
Tier 2 Water Quality
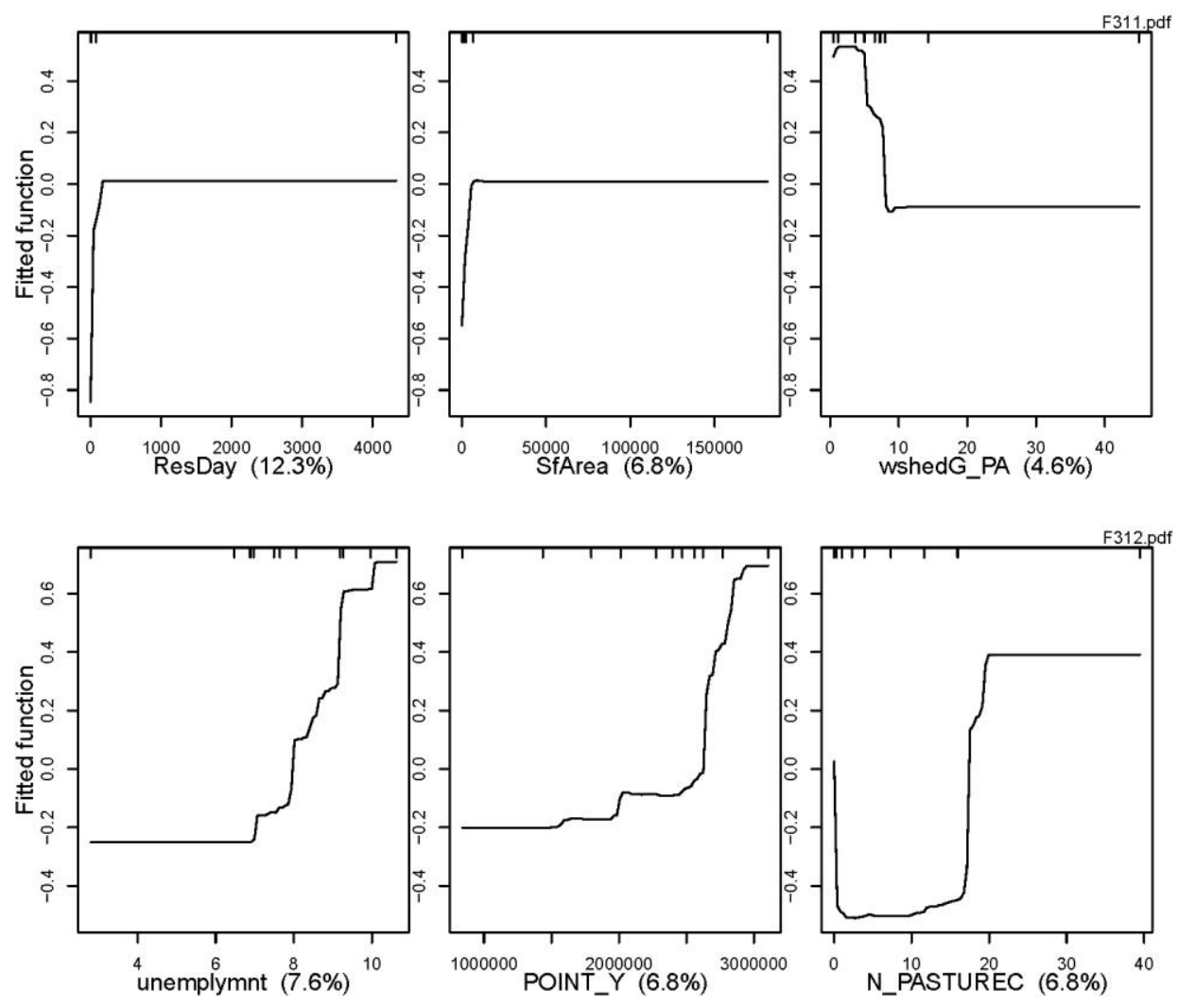

\section{Tier 3 Water Quality}
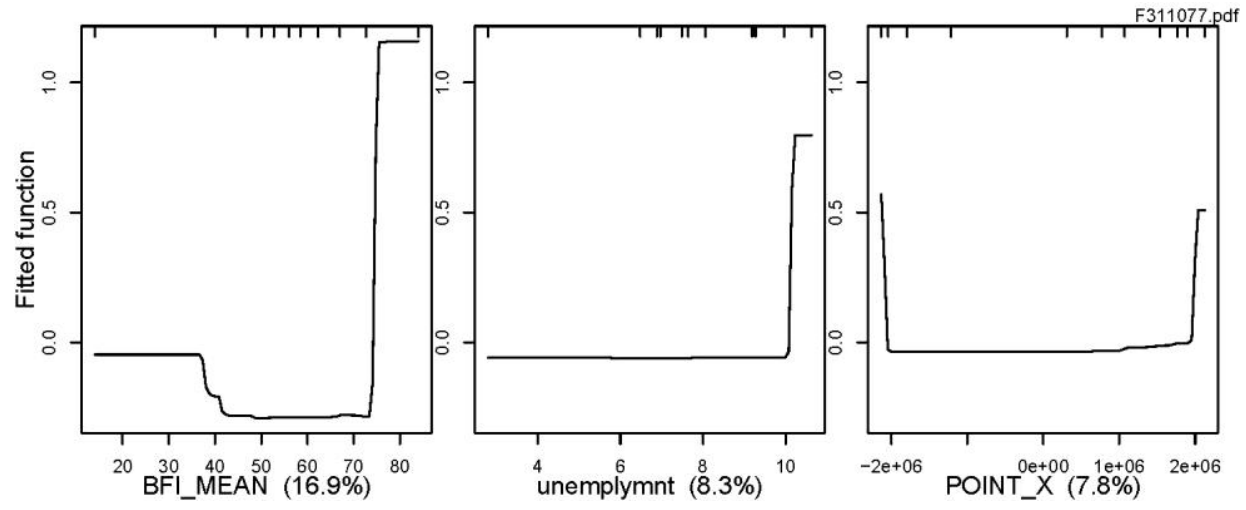

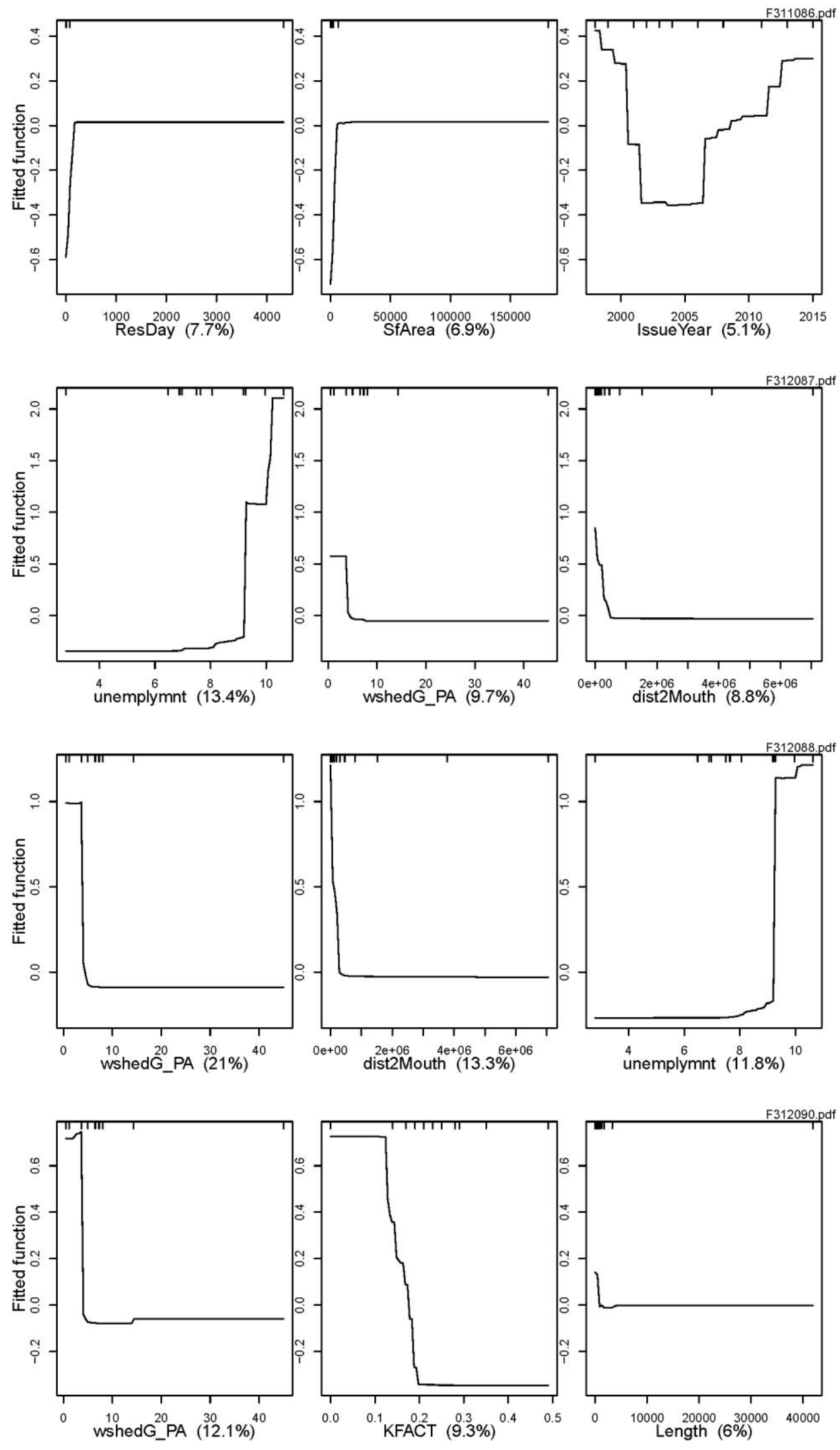

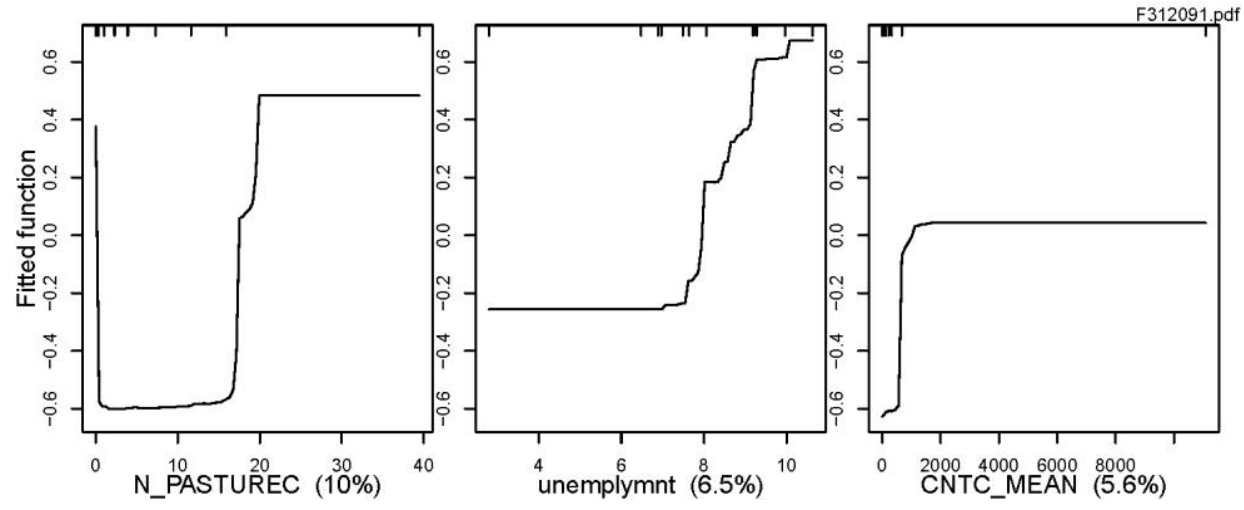

\section{Tier 2 Biodiversity}
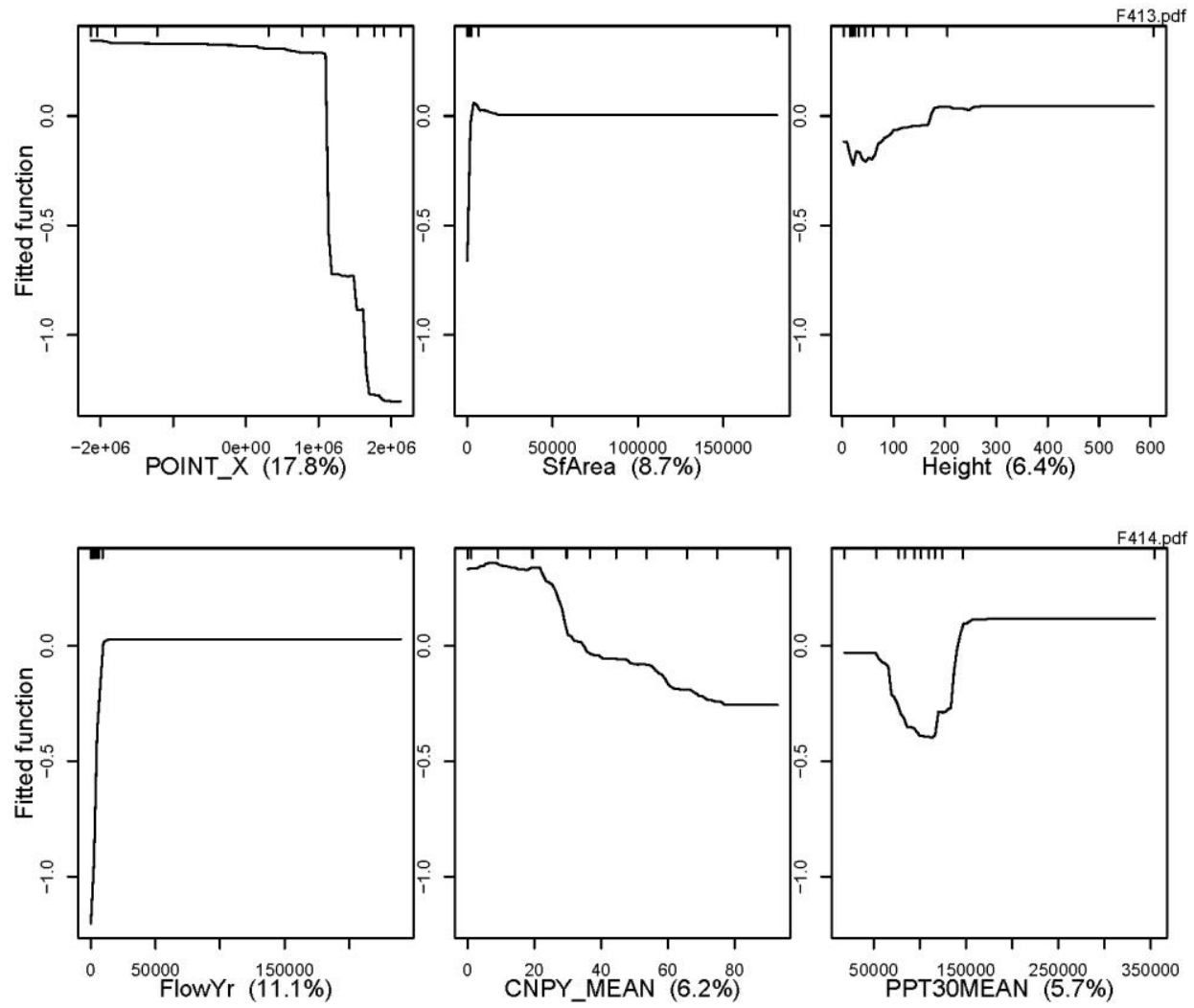


\section{Tier 3 Biodiversity}
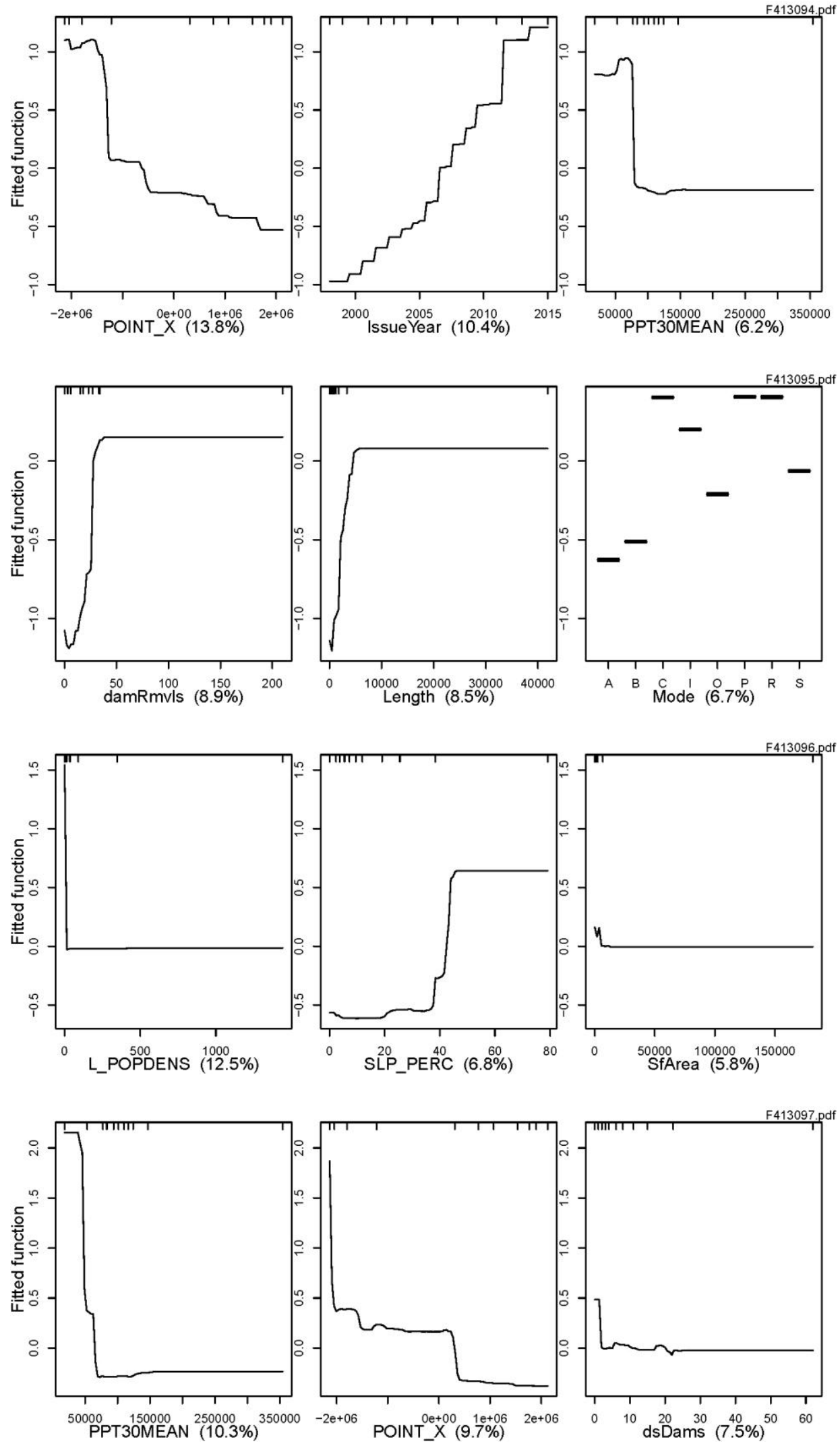

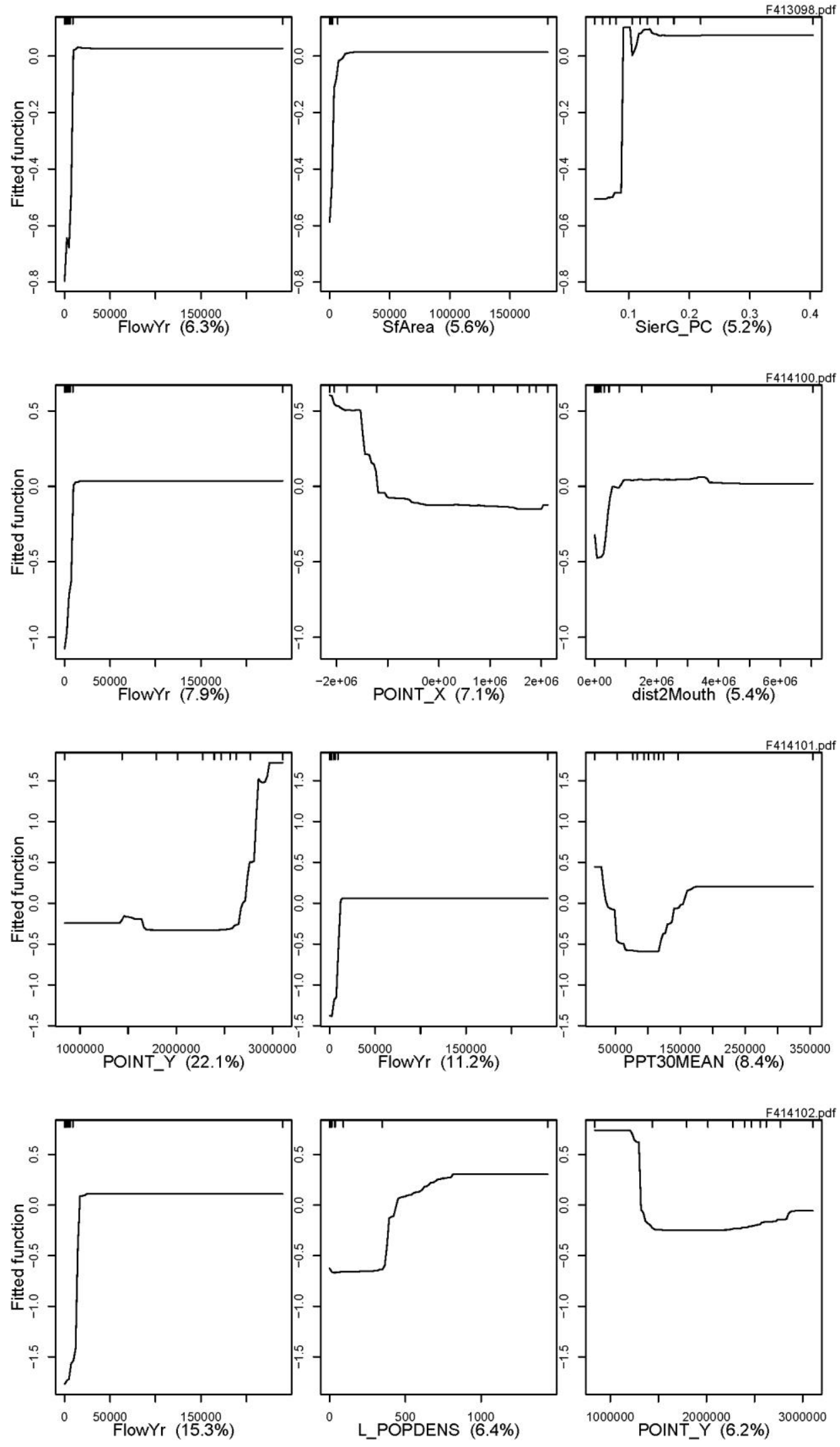
Tier 2 Habitat
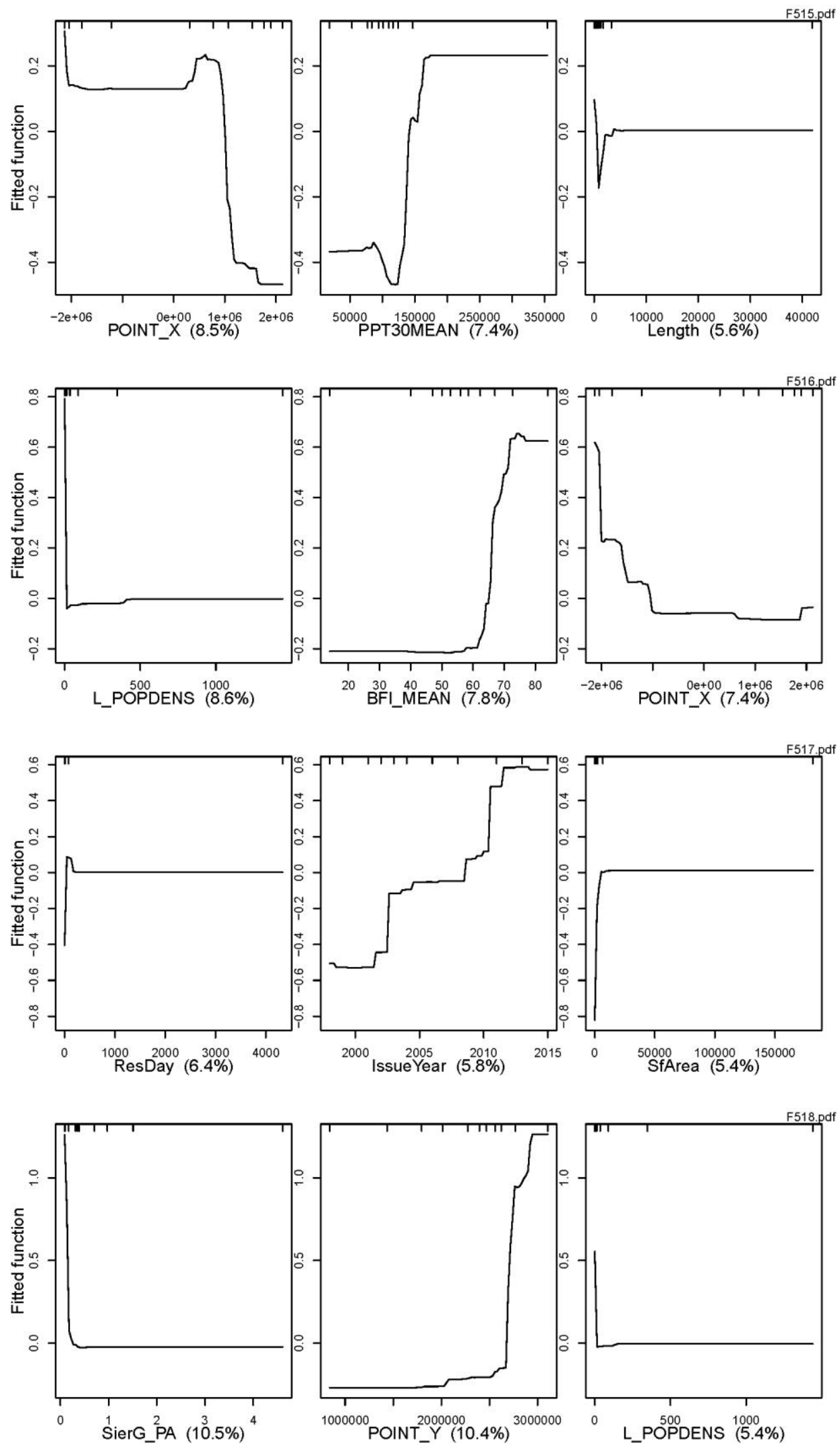
Tier 3 Habitat
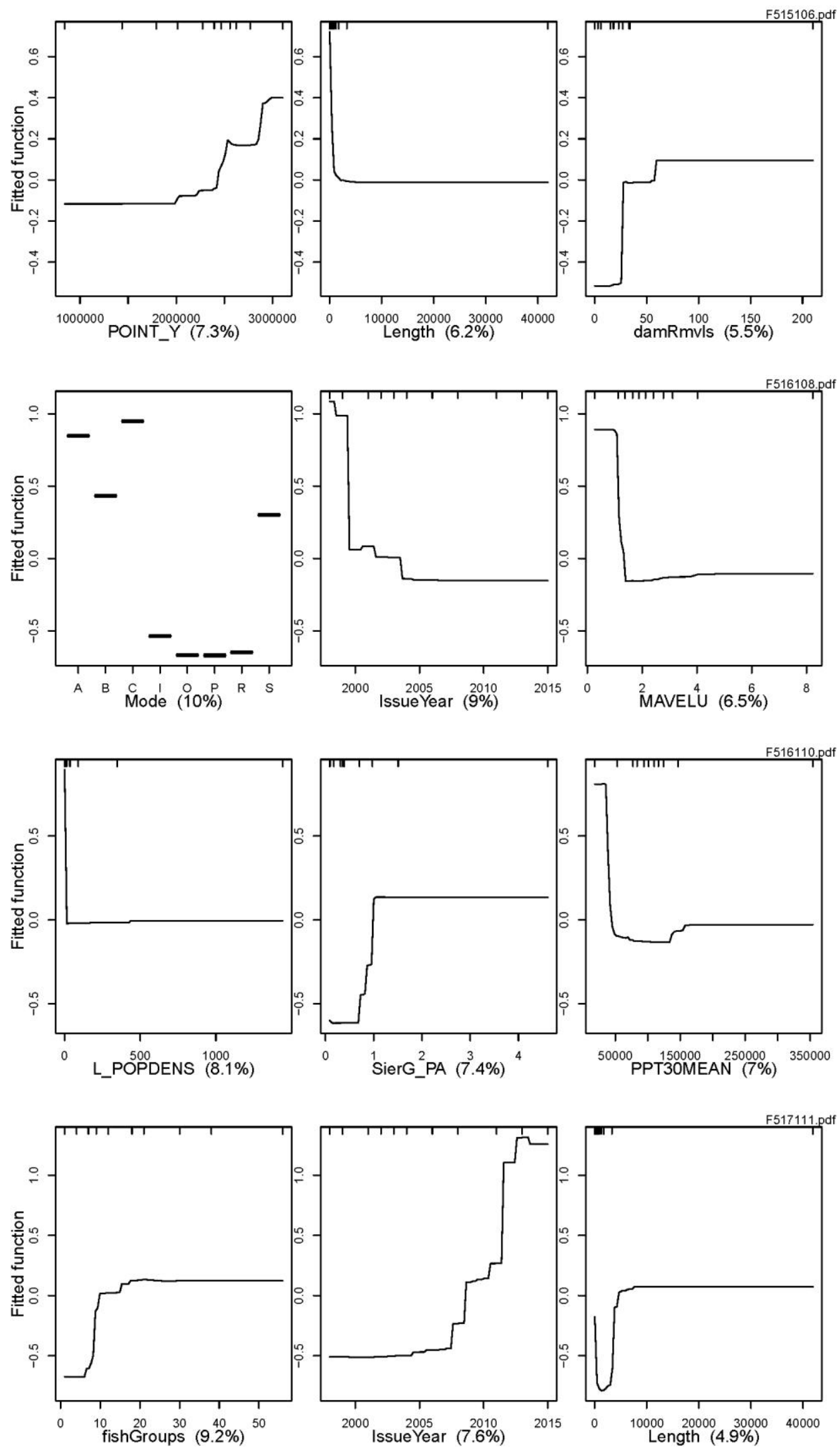

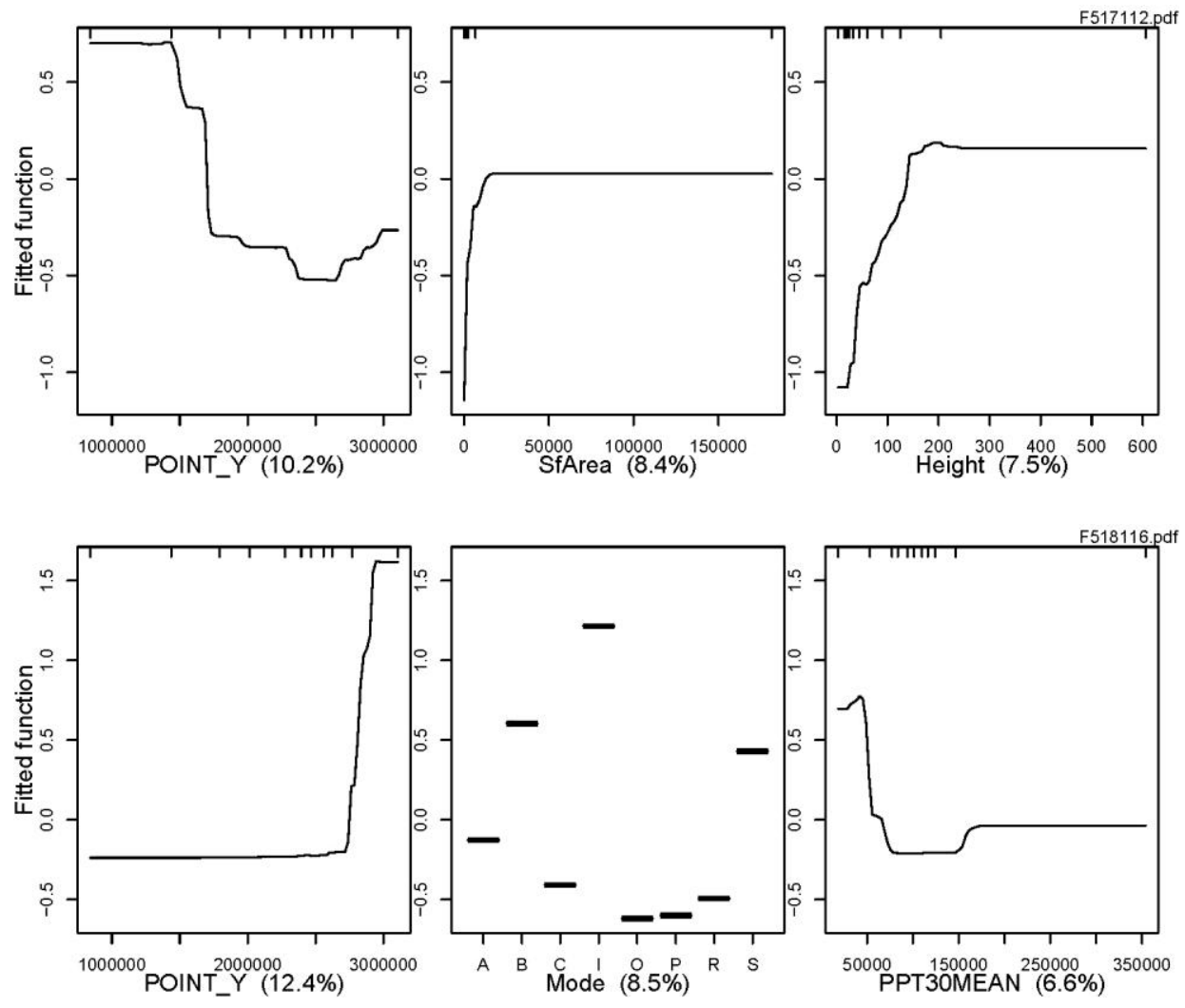

\section{Tier 2 Recreation}
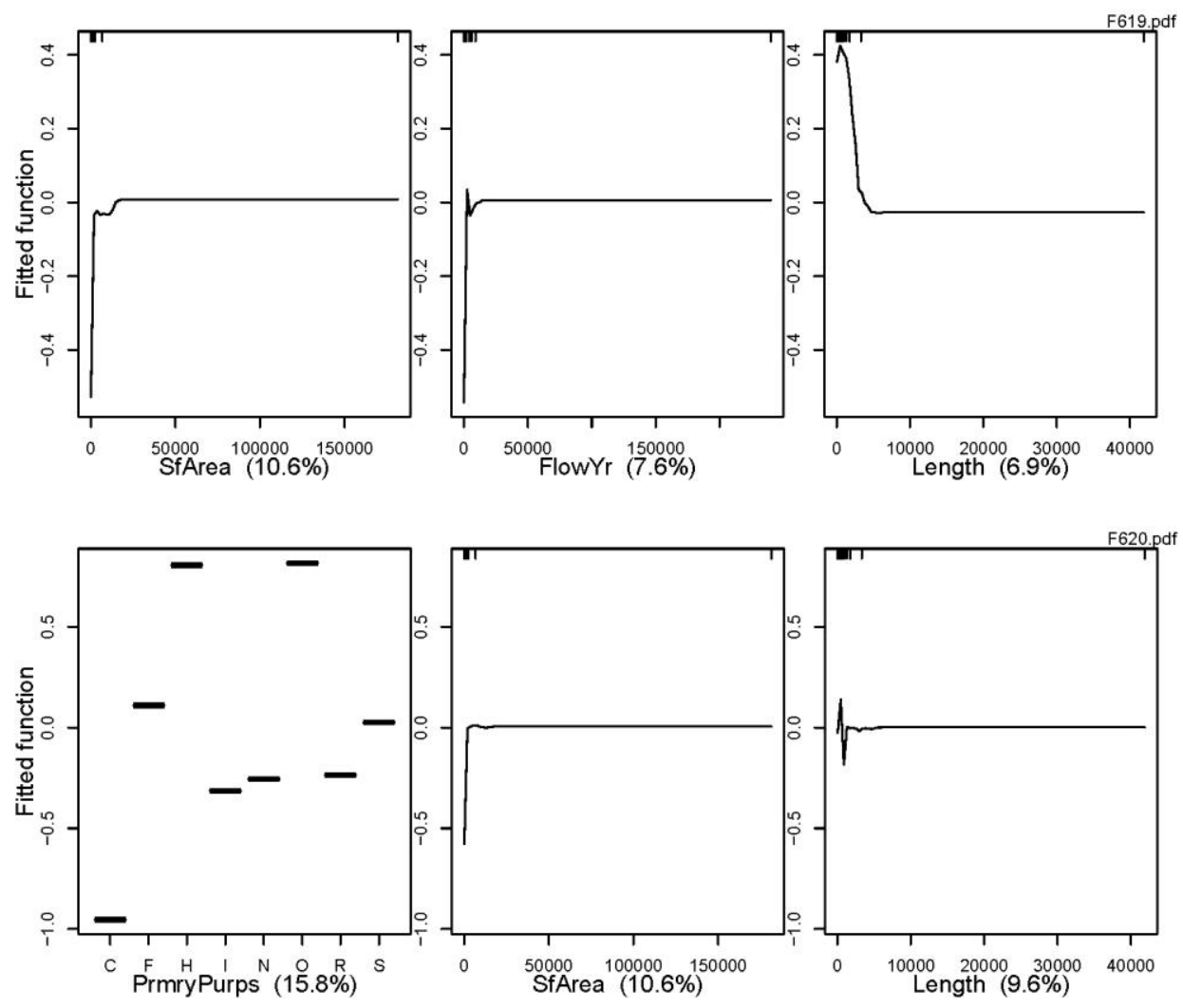
Tier 3 Recreation
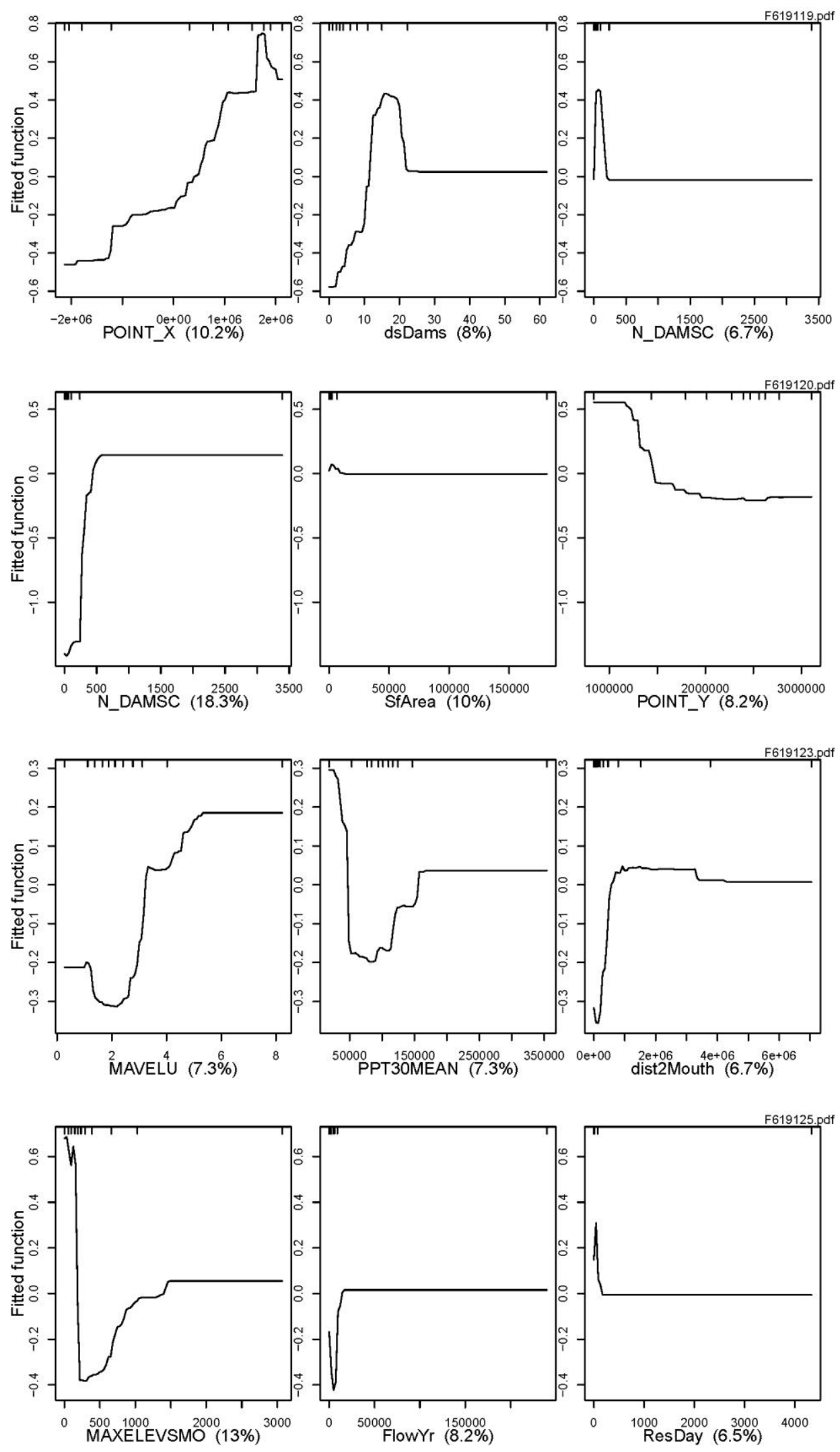

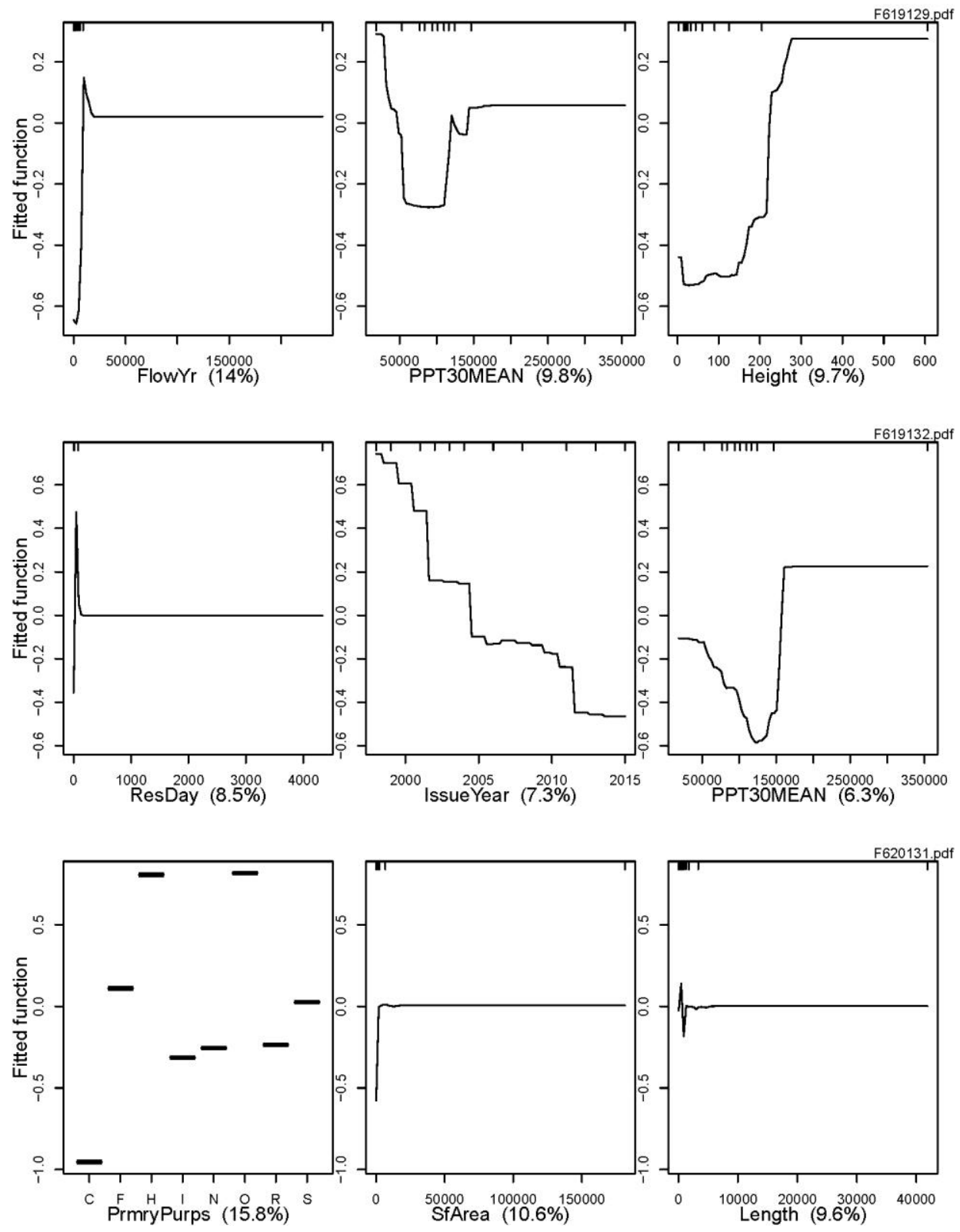